\title{
Antibiotic resistance
}

\author{
Proceedings of a symposium held on 12 July 1996 at the University of Southampton \\ Edited by S. G. B. AMYES and C. G. GEMMELL* \\ Department of Medical Microbiology, The Medical School, University of Edinburgh, Teviot Place, Edinburgh \\ EH8 9AG and *Department of Bacteriology, The Medical School, University of Glasgow, Royal Infirmary, 86 \\ Castle Street, Glasgow G4 OSF
}

\section{Introduction}

In 1991, a meeting on Antibiotic Resistance was held at Addenbrooke's Hospital, Cambridge, with the Proceedings published subsequently in the Journal of Medical Microbiology. This highly successful event attracted much attention. However, in the last 6 years there have been many changes in bacterial resistance to antibiotics, particularly in bacteria associated with nosocomial infection. The original meeting sponsors, Bayer (UK) plc, kindly agreed to arrange a subsequent symposium, held at the University of Southampton on 12 July 1996 as a satellite to the Summer Meeting of the Pathological Society of Great Britain and Ireland. This latest symposium comprised papers on nosocomial pathogens, the epidemiology of resistance in particular infections, reviews of the mechanisms of resistance to specific antibiotic groups, and a final presentation that examined the philosophy of antibiotic resistance. This composite review provides a detailed summary of the papers presented at this symposium.

\section{Nosocomial gram-negative infection}

\section{W. R. Gransden}

Department of Microbiology, United Medical and Dental Schools of Guy's and St Thomas' Hospitals, Guy's Campus, London SE1 9RT

\section{Introduction}

Streptococci and staphylococci were predominant pathogens early this century [1], but the introduction of antibiotics lead to their decline and gram-negative infections became prominent [2]. Although a resur-

Received 5 Sept. 1996; revised version accepted 18 Oct. 1996.

Corresponding author: Professor S. G. B. Amyes. gence of gram-positive infections followed, gramnegative bacteria continued to cause much nosocomial sepsis. Both Pseudomonas spp. and non-pseudomonas gram-negative non-fermenting pathogens were recognised as increasingly important nosocomial pathogens $[3,4]$. Among gram-negative bacilli, acquired resistance to aminoglycosides, $\beta$-lactam agents and quinolones has evolved [5]. Therefore, in many hospitals, infections now occur not only with resistant strains of traditionally susceptible bacteria, such as Escherichia coli and klebsiellae, but also with more inherently resistant gram-negative organisms such as Enterobacter, Serratia, Pseudomonas and Acinetobacter spp. $[5,6]$. Furthermore, gram-negative organisms producing extended spectrum $\beta$-lactamases (ESBLs), particularly Klebsiella pneumoniae in hospital patients, have often caused outbreaks [7, 8]. Finally, there are infections with newly recognised pathogens, such as Stenotrophomonas maltophilia, that are inherently resistant to multiple antibiotics.

Despite increasing reports of multi-drug-resistant gram-negative nosocomial infections, it was not our impression that these organisms were a major problem at Guy's Hospital, although we have many high risk patients. The aim of this study was to define the range of nosocomial gram-negative infections and to assess current susceptibility patterns by analysis of data derived from the laboratory's own computing system and a database of those patients with clinically significant positive blood cultures.

\section{Materials and methods}

Patients. Guy's Hospital is a teaching hospital, part of the Guy's and St Thomas' Hospital Trust, which serves the local population in south-east London and tertiary referrals. Services include general medicine, renal medicine, general, cardiothoracic and transplant surgery, haematology and oncology, adult and paediatric intensive care. 
Data sources. Data were obtained from the microbiology laboratory's computer system for all samples from hospital inpatients in 1995. A computer program generated a list of all results from samples for which antimicrobial susceptibility tests were performed. The susceptibility profiles were analysed after exclusion of repeat isolates with the same susceptibility pattern from individual patients within a period of 1 month [9]. Medical microbiologists kept daily prospective records of clinical and microbiological data on all patients with clinically significant blood cultures [10]. The focus of infection was determined on the basis of supporting microbiological evidence of a culture from the site, or on clinical grounds if cultures were not available.

Microbiology. Organisms were identified by standard methods, with antimicrobial disk susceptibility testing used for routine isolates and a broth micro-dilution technique for blood-culture isolates. The following breakpoints $(\mathrm{mg} / \mathrm{L})$ were used in the interpretation of MIC results: co-amoxiclav 8, cefuroxime 4 , ceftazidime 2 for Enterobacteriaceae and 8 for Pseudomonas spp., ciprofloxacin 1 for Enterobacteriaceae and 4 for Pseudomonas spp., gentamicin 4 and imipenem 4. A confidence interval of $95 \%$ was used to assess the significance of differences in the percentages of strains resistant to individual antibiotics.

\section{Results}

Routine isolates. During 1995, 47878 samples from patients in Guy's Hospital underwent culture in the Department of Microbiology. The most frequent organisms isolated are shown in Table 1, together with their susceptibility to first-line antibiotics. The two most common organisms (from the total of 3018 isolates excluding duplicates) were E. coli (1192 patient isolates) and Pseudomonas aeruginosa (572), followed by Klebsiella, Enterobacter and Acinetobacter spp. The prevalence of amoxycillin resistance was high, found in one-half of all E. coli and almost one- fifth of Proteus mirabilis isolates. Co-amoxiclav was considerably more active, but almost $7 \%$ of the $E$. coli hospital isolates were resistant in vitro to the combination. Resistance to cefuroxime was low for $E$. coli but present in almost $10 \%$ of klebsiellae. For the most frequently isolated Enterobacteriaceae, ciprofloxacin resistance was unusual, but was observed in Serratia marcescens (40.5\%), Acinetobacter spp. (15.5\%) and Citrobacter freundii (12.5\%). Gentamicin resistance was detected in $11.4 \%$ of Acinetobacter spp., 9.3\% of C. freundii and $7.9 \%$ of Klebsiella spp., but was otherwise uncommon among the Enterobacteriaceae. Comparison of $P$. aeruginosa, Pseudomonas spp. and St. maltophilia demonstrated increasing resistance to azlocillin, imipenem, ceftazidime, ciprofloxacin and gentamicin - for each of these compounds, $P$. aeruginosa was the most susceptible of these three organisms and St. maltophilia the least, with other Pseudomonas spp. intermediate between the two.

Some isolates were selected, generally because of resistance to appropriate first-line agents, for further susceptibility testing. Nine of 39 Klebsiella spp. tested were resistant to ceftazidime and two to amikacin, but none to imipenem. Among $59 \mathrm{E}$. coli isolates, three were resistant to ceftazidime, but none to either amikacin or imipenem. The corresponding figures for 42 Enterobacter cloacae isolates were nine resistant to ceftazidime, none to amikacin and one to imipenem. Acinetobacter spp. were rather less susceptible, with 18 of 42 isolates resistant to ceftazidime, three of 39 to amikacin and two of 39 to imipenem.

Significant blood culture isolates. There were 524 episodes of clinically significant bacteraemia. Hospital-acquired isolates accounted for $390(74 \%)$ episodes and, of these, $150(38 \%)$ were caused by gram-negative organisms. The foci of infection associated with the 150 gram-negative blood culture isolates were, in order of frequency, intravascular access devices (44), urinary tract (24), lower respiratory tract (14), alimentary tract

Table 1. Antibiotic resistance patterns amongst organisms isolated from general patients - Guy's Hospital 1995

\begin{tabular}{|c|c|c|c|c|c|c|}
\hline \multirow[b]{2}{*}{ Species } & \multirow[b]{2}{*}{$\mathrm{n}$} & \multicolumn{5}{|c|}{ Percentage of isolates resistant to } \\
\hline & & Amoxycillin & Co-amoxiclav & Cefuroxime & Ciprofloxacin & Gentamicin \\
\hline E. coli & 1191 & 49.5 & 6.9 & 2.6 & 1.8 & 0.8 \\
\hline Ent. cloacae & 237 & 98.7 & 98.7 & 40.2 & 2.1 & 0.4 \\
\hline Ent. aerogenes & 28 & 96.4 & 89.3 & 32.1 & 0 & 0 \\
\hline Klebsiella spp. & 306 & 99.3 & 10.9 & 9.5 & 3.9 & 7.9 \\
\hline Pr. mirabilis & 199 & 19.3 & 0 & 0 & 0.5 & 0.5 \\
\hline Pr. vulgaris & 27 & 96.3 & 7.4 & 88.9 & 0 & 0 \\
\hline Acinetobacter spp. & 114 & 48.1 & 11.0 & 47.7 & 15.5 & 11.4 \\
\hline C. freundii & 43 & 98.0 & 95.0 & 55.0 & 12.5 & 9.3 \\
\hline C. koseri & 30 & 100 & 6.7 & 6.9 & 0 & 0 \\
\hline Ser. marcescens & 74 & 100 & 100 & 100 & 40.5 & 0 \\
\hline Morganella morganii & 32 & 100 & 100 & 87.5 & 0 & 0 \\
\hline$P$ aeruginosa & 572 & $8.1^{*}$ & $4.1^{\dagger}$ & $3.7^{\ddagger}$ & 9.8 & 7.2 \\
\hline Pseudomonas spp. & 92 & $13.6^{*}$ & $10.3^{\dagger}$ & $12.5^{\ddagger}$ & 24.2 & 15.4 \\
\hline St. maltophilia & 73 & $18.1^{*}$ & $100^{\dagger}$ & $29.2^{\ddagger}$ & 70.4 & 76.7 \\
\hline
\end{tabular}

*Percentage resistant to azlocillin.

${ }^{\dagger}$ Percentage resistant to imipenem.

${ }^{\ddagger}$ Percentage resistant to ceftazidime. 
(11), surgical wound (7), biliary tract (7) and others (4), while in 39 cases no focus was identified.

Susceptibility data were available for 132 of the gramnegative blood culture isolates. Table 2 lists the results for the 120 most frequent isolates; the others were: Proteus spp. (4), Agrobacterium radiobacter (2), C. freundii (1), C. koseri (1), Commamonas acidovorans (1), Erwinia herbicola (1), Morganella morganii (1) and Yersinia enterocolitica (1).

Comparison of the distribution of bacteria from blood with those from all samples showed that the following were relatively under-represented among blood culture isolates: E. coli $(22.0 \%$ versus $38.2 \%$, respectively) and Proteus spp. (3.0\% versus $8.0 \%)$. In contrast, other genera were relatively more common among blood culture isolates: Klebsiella spp. (16.7\% versus $10.0 \%$ ), Enterobacter spp. (19.7\% versus $9.2 \%)$, Ser. marcescens $(10.6 \%$ versus $2.6 \%)$ and St. maltophilia $(7.6 \%$ versus $2.3 \%)$. However, $P$. aeruginosa and Acinetobacter spp. were similarly represented in the two groups ( $18.9 \%$ versus $18.4 \%$ and $5.2 \%$ versus $3.6 \%$, respectively).

MIC data suggested that only two episodes of bacteraemia were associated with klebsiellae producing ESBLs. They occurred in the same patient and the organism was acquired in another hospital before transfer to Guy's Hospital paediatric intensive care unit. The percentages of E. coli, Klebsiella spp. and Acinetobacter spp. susceptible to ciprofloxacin were significantly higher in blood isolates compared with others, and the same differences were noted for Acinetobacter spp. with gentamicin and $P$. aeruginosa with ceftazidime. In contrast, blood isolates of $E$. coli, klebsiellae and Ent. cloacae were resistant to cefuroxime significantly more often at a breakpoint of $4 \mathrm{mg} / \mathrm{L}$, although at $16 \mathrm{mg} / \mathrm{L}$ there was no significant difference.

Multiresistant strains. Ten $(7.6 \%)$ blood culture isolates were resistant to three or more of gentamicin, amikacin, ciprofloxacin, imipenem and ceftazidime. They included eight St. maltophilia, one Ag. radiobacter and one $K$. pneumoniae. In nine cases, the focus of infection was an intravascular access site, while the last focus was not identified. All were resistant to gentamicin and amikacin, eight to imipenem, three to ceftazidime, and one to ciprofloxacin. All 10 patients survived the episode.

\section{Discussion}

Computer analysis of all isolates from the diagnostic laboratory should provide a ready supply of antimicrobial resistance data to define the nature and extent of nosocomial infection with resistant organisms, but there are several disadvantages. Repeated samples should be excluded and it is difficult to distinguish contaminating from infecting organisms. The technique employed in this study did not permit the detection of multiresistant isolates. More detailed surveillance is required for an accurate assessment. The optimum method remains unclear [11] and it has been suggested that monitoring infections at specific body sites may lead to earlier detection of changes in antimicrobial resistance compared with surveillance of blood cultures [12]. Although the number of gram-negative septicaemias was relatively low in the present study, the results suggest that the organisms found in blood cultures tend to be more susceptible to certain antibiotics. A recent Swedish study noted that blood isolates were generally more sensitive to cephalosporins than urine and wound isolates collected at the same time [13]. McGowan considered that nosocomial blood stream infection was a useful indicator of overall changes in hospitalacquired infection [3]. Moller [14] found that there was good concordance between the distribution of isolates in blood and other sites although, as in the present study, there were relatively few $E$. coli isolates from blood.

Analysis of the blood culture data may give a broad indication of the sites of gram-negative infections, although there is a large bias towards intravascular access-associated sepsis which is much more likely to lead to a positive blood culture than infection at other sites of the body. Although the most recent results published by the National Survey of Nosocomial Infection in the United Kingdom [15] do not distinguish between gram-positive and gram-negative infections, it is likely that the urinary tract, respiratory tract and surgical wounds remain the most common

Table 2. Antibiotic resistance patterns amongst organisms isolated from blood cultures - Guy's Hospital 1995

\begin{tabular}{|c|c|c|c|c|c|c|}
\hline \multirow{2}{*}{$\begin{array}{l}\text { Organisms } \\
\text { isolated }\end{array}$} & \multirow[b]{2}{*}{$\mathrm{n}$} & \multicolumn{5}{|c|}{ Percentage of isolates resistant to } \\
\hline & & Co-amoxiclav & Cefuroxime & Ceftazidime & Ciprofloxacin & Gentamicin \\
\hline Enterobacter spp. & 27 & 96.2 & 85.1 & 25.9 & 0 & 0 \\
\hline E. coli & 24 & 12.5 & 25.0 & 8.3 & 0 & 4.2 \\
\hline Klebsiella spp. & 20 & 10.0 & 30.0 & 10.0 & 5.0 & 5.0 \\
\hline Ser. marcescens & 10 & 100 & 100 & 0 & 20.0 & 0 \\
\hline Acinetobacter spp. & 6 & 16.7 & 66.7 & 0 & 0 & 0 \\
\hline P. aeruginosa & 23 & $4.3^{*}$ & $4.3^{\dagger}$ & 0 & 4.3 & 13.0 \\
\hline St. maltophilia & 10 & $10.0^{*}$ & $100^{\dagger}$ & 10.0 & 10.0 & 80.0 \\
\hline
\end{tabular}

*Percentage resistant to azlocillin.

†Percentage resistant to imipenem 
sources. These, together with intestinal foci, have been reported $[16,17]$ to be the main sites of nosocomial infection. Caution must always be observed before interpreting blood culture data as representative of general infection patterns.

The overall susceptibility data in the present study were for a limited range of antimicrobial agents those considered to be 'first-line' agents. Although 'second-line' antibiotics were also tested, they were not included in the analysis as they would have reflected the susceptibility of a selected group of more resistant bacteria. The more detailed analysis of MIC results from blood culture isolates avoids this bias, as they were all tested routinely against a full range of agents. However, the number of isolates included is inevitably much smaller. Larger numbers could be accrued by a study of longer duration or by enrolling several centres simultaneously. The latter approach has been used in the observational surveys of the Public Health Laboratory Service (PHLS) [18].

In general, the antibiotic resistance patterns accord with the ranges reported in a recent survey of European intensive care and oncology units [19]. Aminoglycoside resistance at Guy's Hospital remains uncommon and other centres have reported similar results [4] despite continued, although generally cautious, use of the agents. In particular, resistance to amikacin (a restricted drug at Guy's Hospital) appears to be exceptional, apart from in St. maltophilia. Among Enterobacteriaceae, resistance to ciprofloxacin was more prevalent than to gentamicin. Higher levels of quinolone resistance have been found elsewhere [20], notably in strains of $E$. coli from patients with cancer and neutropenia [21, 22], a finding attributed in part to the use of these agents for prophylaxis against gram-negative sepsis. However, this has not been a universal finding [23].

Only tentative conclusions can be drawn from the data presented here concerning the classes of $\beta$-lactamase likely to be present in isolates. While there are well recognised relationships between $\beta$-lactamases and antibiograms, the latter should, ideally, be used to screen for the presence of particular $\beta$-lactamases [24]. From the blood culture data there is strong evidence for the presence of ESBLs in Klebsiella spp. One centre in the UK has reported a large and prolonged outbreak of resistant Klebsiella spp. leading to endemicity with a high carriage rate [8]. Mayer [25] has noted that klebsiellae are often the index species for the dissemination of nosocomial plasmids. In one centre in France, $40 \%$ of $K$. pneumoniae isolates are resistant to ceftazidime and aztreonam; most of these are also resistant to quinolones and aminoglycosides [26].

Only $38 \%$ of nosocomial bacteraemias were associated with gram-negative bacilli. Resistance did not present great difficulty; while $7.5 \%$ of gram-negative isolates from blood cultures were multiresistant, the majority of these were St. maltophilia infections associated with intravascular access sites and caused no mortality. Multiresistance is not as great in Guy's Hospital as might be predicted from some reports $[27,28]$ and we are fortunate not to have observed, so far, the problems with resistant strains encountered elsewhere and the prospect of transferable carbapenem resistance [29]. It is unclear why the problem varies in geographic areas [30], but we believe control has been successful at Guy's Hospital because of a firm antibiotic policy, close involvement of medical microbiologists in the prevention and management of infection in vulnerable groups, and good infection control practice.

\section{Nosocomial gram-positive infection}

B. Cookson, D. Morrison and R. Marples

Laboratory of Hospital Infection, Central Public Health Laboratory, 61 Colindale Avenue, London NW9 5HT

\section{Introduction}

Nosocomial gram-positive infection has a high profile in the 1990s. There are two major reasons for this. Firstly, hospital infection is now regarded as a potential quality indicator of the whole health care organisation [31]; gram-positive organisms comprise at least onethird of the organisms causing hospital infection. Secondly, antibiotic resistance is emerging in many parts of the world in gram-positive nosocomial pathogens, such as methicillin-resistant Staphylococcus aureus (MRSA) and enterococci resistant to glycopeptides such as vancomycin (VRE). There is also the threat of vancomycin resistance transferring to MRSA. The media are heralding the end of the antibiotic era. A recent WHO report expressed concern about the threat of antibiotic-resistant gram-positive and gramnegative pathogens [32]. The problem of another grampositive bacterium, Clostridium difficile, which is emerging as a potential marker for quality of antibiotic prescribing practice, is not discussed in this contribution. Guidelines for control and prevention were described recently [33].

Approximately one-half of the infections occurring in hospitals originate from the community; patients are admitted with or incubating these infections which can then present opportunities for cross-infection to others. The other half are acquired in hospitals, mainly from the patients' own normal microbiota or from other patients, staff and the environment. Antibiotic resistance has, ironically, provided more readily identifiable strain markers to enable greater understanding of the more complex dynamics of hospital infection. It is known from studies of MRSA over the last two decades and, more recently, VRE that policies for 
control have to consider inter-hospital transfers of staff and patients and re-admissions to hospitals. There are also additional interactions with other institutions such as elderly care and nursing homes.

In certain respects, history is repeating itself. In the 1950 s, virulent $S$. aureus (phage type 80/81) strains were the major driving force to improve standards of infection control in the UK and many other countries.

\section{Changing patterns of nosocomial gram-positive infections}

The first PHLS survey in 1960 [34] described the organisms causing surgical site infection (SSI) in 3276 wounds in 21 hospitals in England and Wales. There was a sepsis rate of $9.7 \%$, but there were few data on the organisms causing these infections. $S$. aureus was the commonest organism isolated, followed by E. coli. The invertigators were particularly concerned about the phage types of $S$. aureus causing infections. Nasal carriage of the 'virulent' type 80 strain was a significant risk factor for sepsis but, as with the current epidemic MRSA (EMRSA), there was a geographical association for this strain in that it was not found in three hospitals in the North of England. Nasal staphylococcal carriage did not, overall, increase the risk of sepsis, which was related to age, length of preoperative stay, length of incision $(>6 \mathrm{~cm})$, duration of operation and use of a drainage tube.

Some interesting data on changing trends in grampositive infection come from the National Nosocomial Infection Surveillance System (NNIS) established in the USA in 1970 [35]. However, these and other studies discussed here must be interpreted in the light of dramatic changes in surgical and invasive procedures (e.g., day and fibre-optic surgery, increasing use of catheters, implanted prostheses and other devices), and changes in patient populations and treatments (e.g., age, immunosuppression and transplantation). Hospitals participating or studied have changed with time but, more importantly, the surveillance process has not been modified to compensate for the decreasing lengths of hospital stay. This makes it essential to consider post-discharge surveillance. However, this is often omitted or performed with non-standardised or unvalidated methods [36]. Hospital infection is thus being displaced into the community. Lack of clinical sampling in hospitals threatens the alert organism system and skews the data recorded in the hospital to the most ill patients, or perhaps certain specialties. New strategies for outbreak control must also take this into account; routine discharge screening from wards suspected or known to be affected with MRSA or other resistant organisms must be considered [37].

Risk factor data are available and could assist interpretation of trends, e.g., for SSIs and duration and type of device usage [38]. However, it would also be important for analyses of antibiotic resistance trends to access data on total antibiotic usage, audit of compliance with antibiotic policies, and the extent and correct use of antibiotic prophylaxis.

The USA NNIS data suggest changing patterns in organisms causing hospital infection between 1980 and 1986-89 [39]. There were decreases in certain gram-negative pathogens (E. coli by $20 \%$ and Klebsiella spp. by $2 \%$ ), whereas there was a doubling of coagulase-negative staphylococcal infections, associated with an increased number of blood stream infections, from $4 \%$ to $9 \%$. There was a slight increase (by $1-2 \%$ ) in infections caused by enterococci and $S$. aureus, but also in infections caused by $P$. aeruginosa and Enterobacter spp. Currently, Enterococcus spp. are the second, $S$. aureus the fourth, and coagulase-negative staphylococci (CNS) the fifth most common pathogens if the non-E-coli members of the Enterobacteriaceae are disregarded.

Overall, the incidence of MRSA has risen in the USA from $2.4 \%$ of all isolates in 1975 to $29 \%$ in 1991 . Hospitals with $>500$ beds have the highest incidence $(38.3 \%)$, but increases are being seen in hospitals of all sizes, albeit with temporal differences [40]. Methicillin resistance in CNS increased 300\% over this period and, like MRSA, increases are occurring in hospitals of all sizes, although the highest incidence is seen in the larger hospitals.

In the 35 years following the first 1960 PHLS survey, there have been two repeats of National UK Studies. The results of a 19-centre PHLS audit study are about to be published and there are many other initiatives including a PHLS Nosocomial Infection National Surveillance Scheme for England. The preliminary results of the second UK National Prevalence Survey organism data indicate increases in gram-positive infections from $30 \%$ to $39.7 \%$ compared with the previous study [41]. Enterococci increased from $4 \%$ to $7 \%$, and CNS from $3 \%$ to $7.7 \%$, but $S$. aureus decreased from $17.6 \%$ to $14.7 \%$. However, there was an increase in MRSA from $0 \%$ to $5 \%$, and MRSA accounted for 14 of the 228 SSIs $(15 \%$ of all $S$. aureus SSIs.) (B. Cookson and colleagues, unpublished observations). Clearly these data will need to be stratified further by site of infection. For SSI they should be further stratified by class of wound. Several studies have shown that $S$. aureus is a commoner cause of infection in clean wounds, with gramnegative bacilli and enterococci associated with the more contaminated or dirty wounds [42]. There are many differences between the two UK prevalence studies and comparisons will be extremely difficult.

\section{MRSA}

MRSA re-emerged as a significant cause of hospital infection in the early 1980 s, soon after the last 
Prevalence Survey. Epidemic MRSA (EMRSA) causing infection in two or more patients in at least two hospitals were characterised [43]. However, some MRSA strains spread much more widely than others and might be termed 'Super' EMRSA (SEMRSA) or re-defined as genuine EMRSA. In the 1980s, these EMRSA were largely (but not exclusively) causing outbreaks in a particular UK region.

The revised UK guidelines for MRSA control [44] recommended that contact be made with the reference laboratory and that the measures taken would be influenced by whether the strain was a known EMRSA. The continuing problems with MRSA in the 1990s are resulting in a re-appraisal of control methods, including addressing infection control precautions in nursing and elderly care homes. One study has shown that EMRSA-16 has affected three of eight nursing, and three of seven residential, homes [45]. Fourteen of 350 patients and one of 72 staff were colonised. In three instances, spread occurred between patients sharing rooms and to 11 patients not sharing rooms. Similar results have been seen in two other homes affected by EMRSA-3 and EMRSA-1 (B. Cookson, unpublished observations). There also seems to be an emerging realisation of the possibility of MRSA acquisition within the family, and, rarely, even pets may constitute a reservoir.

EMRSA-15 emerged in the West Midlands, but has now spread. A recent audit suggested that $40 \%$ of colonised patients became infected (I. Blair, personal communication). EMRSA-16 caused a large outbreak in the hospital in Northamptonshire affected originally. Eighty-three $(21 \%)$ of the 400 patients involved over a 20 -month period were infected. This comprised $4 \%$ of the hospital's $S$. aureus infections, and the strain caused significantly more chest infections and deaths from septicaemia [46]. EMRSA-16 spread locally, then to West and South London, and thence to the SouthEast of England. Hospitals differ in their experience; some are able to control the organism, whilst others are suffering from significant outbreaks. Spread is now occurring further afield and the Reference Laboratory is reporting on the situation regularly and feeding this information to the newly convened MRSA working party formed by the Hospital Infection Society, Infection Control Nurses Association and the British Society for Antimicrobial Chemotherapy. Typing loads at the Central Public Health Laboratory are immense and criteria for submission of isolates for typing are having little effect. A possible reason for this is that hospitals are increasingly affected by more than one EMRSA and typing is perhaps of more use than ever before.

One hospital reporting to the Reference Laboratory has shown that one-half of wounds colonised with EMRSA-16 have become infected. Orthopaedic wards continue to be affected by EMRSA, and joint replacement infections are often mentioned. The debate over the measures required to control UK MRSA, or indeed the necessity, continue. It is very difficult to determine the relative importance of the many outbreak control measures that have been advocated; they include isolation, effective therapy of cases, increased education, and institution of handwashing agents and antibiotic policies.

Clinical microbiologists are convinced that these newer EMRSA (types 15 and 16) are causing significant infections, and this is supported by two other sources of information. The preliminary univariate analysis of the Second Prevalence Survey (M. Griffin, personal communication) has shown that MRSA colonisation had the highest relative risk (5.09) for hospital-acquired infection. The data from the Communicable Disease Surveillance Centre (CDSC) bacteraemia reporting system also indicate dramatic increases in MRSA infections (D. Speller, personal communication). MRSA infection had remained approximately static $(<2 \%)$ until the 'takeoff' in EMRSA types 15 and 16, with an increase to $8.1 \%$ in 1994 and a worrying $13.6 \%$ for the first 6 months of 1995. EMRSA-15 became ciprofloxacinresistant fairly early on, followed by EMRSA-3; EMRSA-16 was quinolone-resistant $a b$ initio. That the increases are caused by these strains is perhaps supported by the increasing percentage of ciprofloxacin-resistance in the data. However, these hypotheses will have to be investigated further by comparing these data with those in the Reference Laboratory database of referred isolates. Sample migration of reported bacteraemia isolates is a possible (but unlikely) explanation.

Several groups of workers have used mupirocin to eradicate MRSA from the nose and wounds. This should reduce MRSA transmission to staff and then to other patients [47]. High-level mupirocin-resistant MRSA (MIC $\geqslant 256 \mathrm{mg} / \mathrm{L}$ ) were reported in 105 patients from 34 UK centres (14 with EMRSA-16) in the first 6 months of 1994 [48]. The significance of low-level resistance is more difficult to interpret, but it is even more widespread (865 patients from 115 centres; 638 patients from 51 centres with EMRSA-16). However, we are concerned that the agent is becoming abused in that it is used repeatedly on the same patient for prolonged periods, or prophylactically, in situations where it is impossible to prevent MRSA re-colonisation, and 'blanket use' after initial MRSA screening of all patients and staff. Sometimes it has been used on staff without establishing if the carriage is transient. At the other extreme, the full extent of carriage has not been established and there has been no consideration of combination with systemic agents. Judicious and careful control of its use is imperative and the use of alternative agents (old and new) is being explored for these strains. 


\section{Enterococci}

These organisms have become labelled as the nosocomial pathogens of the 1990s [49]. Some of the data should be viewed with caution in that enterococci are often isolated in mixed culture from many infected sites, especially wounds and perhaps urine. However, stratifying the USA NNIS data by site of isolation, they are still the third commonest pathogen from blood. Strains of VRE are often also resistant to high levels of gentamicin, thus compromising the standard therapies for these organisms. In the USA, centres are anecdotally describing resistance to vancomycin in up to $50 \%$ of their isolates. The Centers for Disease Control report an increase in resistance from $0.3 \%$ to $7.9 \%$ between 1989 and 1993, with an even more dramatic increase from $0.4 \%$ to $13.6 \%$ amongst ITU isolates [50].

In the UK, the first incidence of VRE occurred in a London hospital renal unit, resulting in a large outbreak involving 41 patients. A number of different strains, mainly Enterococcus faecium but also En. faecalis, were involved and eradication proved difficult [51]. These features are typical of other UK outbreaks. Strains appear to spread rapidly between patients, and heavy environmental contamination is often observed. Contamination of surfaces, such as dripstand hand grips, monitoring devices [52] and computer terminals, and evidence that these organisms survive for up to $30 \mathrm{~min}$ on fingertips [53], suggests that hospital personnel may be involved in transmission.

Since 1987 the spread of enterococcal isolates with acquired vancomycin resistance in UK hospitals has been monitored by the Reference Laboratory. Between 1987 and 1995, 720 patients from 71 hospitals were affected. The number of hospitals with VRE continues to increase each year, with 18,27 and 47 hospitals affected in 1993, 1994 and 1995, respectively [54]. The proportion of En. faecium (86\%) to En. faecalis $(11 \%)$ is the reverse of that seen when all clinical specimens are considered [55], and most (80\%) isolates are of the vanA phenotype. Pulsed-field gel electrophoresis (PFGE) typing performed on a large number of vancomycin-resistant En. faecium (VREM) isolates suggests that, nationally, a large number of heterogeneous strains are involved. In general, each hospital appears to have its own strain or set of strains. However, five epidemic strains have also been observed. These strains, designated epidemic vancomycin resistant En. faecium (EVREM), have been isolated from two or more patients in at least two hospitals. In two instances, the transfer of a patient from a unit at one hospital with a known VRE problem resulted in an outbreak at the receiving unit. One of these epidemic strains, EVREM-3, is particularly worrying as it appears to have a remarkable ability for intra- and inter-hospital spread. Over a 4year period it has been isolated in 13 hospitals in the London area and, more recently, it has caused an outbreak via known patient transfer at a hospital on the South coast. Such epidemic strains have also been reported in the USA. One strain was isolated at seven hospitals in Seattle during a 4-year period [56]. These facts suggest that hospitals should consider screening new patients for VRE, as has been suggested elsewhere [57].

The origin of VRE is an area of intense debate with two theories prevailing. The first suggests that they emerged in the hospital environment following heavy use of vancomycin, possibly acquiring the vancomycin resistance gene from a hitherto uncultured bacterium [58], while the second suggests a link with the use of avoparcin (a glycopeptide growth promoter) in the farming industry [59]. The European Union have banned the use of avoparcin, but more work is clearly required in this area.

\section{Epidemiology of resistance - respiratory tract infections}

\section{J. Thomson}

Department of Medical Microbiology, The Medical School, University of Edinburgh, Teviot Place, Edinburgh EH8 $9 A G$

\section{Introduction}

Increasing levels of resistance to antimicrobial agents are leading to a dwindling resource of treatment options for bacterial infections. Treatment of community-acquired respiratory infections is an area of particular concern, as treatment often has to begin empirically before the causative organism is identified. Several bacterial species are responsible for respiratory tract infections, the three most common being Streptococcus pneumoniae, Haemophilus influenzae and Moraxella catarrhalis. In order to assess critically the threat of increasing antimicrobial resistance, it is necessary to examine, first, trends in the levels of resistance observed and, second, the mechanisms of resistance. This article reviews the incidences and mechanisms of antibiotic resistance in these three organisms.

\section{Haemophilus influenzae}

Ampicillin resistance was first detected in $H$. influenzae in the 1970 s and has risen steadily to the present level of $10-30 \%$ reported by most centres. Current levels of resistance in the UK are detailed in Table 3 [60]. The major mechanism of resistance to $\beta$-lactam drugs in $H$. influenzae is the production of $\beta$-lactamases, and the prevalence of $\beta$-lactamase-producing isolates has increased over the last 20 years. The extent of non- $\beta$ lactamase-mediated resistance has always been difficult to assess and it is possible that $\beta$-lactamase production may be missed by routine testing $[61,62] . \beta$-lactam resistance in strains apparently negative for $\beta$-lactamase 
Table 3. Current levels of antibiotic resistance amongst lower respiratory tract isolates from England and Wales

\begin{tabular}{lccccc}
\hline & \multicolumn{3}{c}{ H. influenzae } & & \multicolumn{2}{c}{ M. catarrhalis } \\
\cline { 2 - 3 } \cline { 5 - 6 } Antibiotic & $\begin{array}{c}\text { Breakpoint } \\
(\mathrm{mg} / \mathrm{L})\end{array}$ & $\begin{array}{c}\text { Resistant } \\
\text { isolates }(\%)\end{array}$ & & $\begin{array}{c}\text { Breakpoint } \\
(\mathrm{mg} / \mathrm{L})\end{array}$ & $\begin{array}{c}\text { Resistant } \\
\text { isolates }(\%)\end{array}$ \\
\hline Amoxycillin & 1.0 & 16.9 & 1.0 & 1.0 & 33.0 \\
Co-amoxiclav & 1.0 & 4.5 & 1.0 & 4.0 \\
Cefuroxime & 1.0 & 5.0 & 1.0 & 2.7 \\
Ciprofloxacin & 1.0 & 0 & 0.5 & 6.0 \\
Erythromycin & 0.5 & 4.2 & 1.0 & 2.7 \\
Tetracycline & 1.0 & 9.6 & 1.0 & 100 \\
Trimethoprim & 1.0 & & & & 2.0 \\
\hline
\end{tabular}

Isolates obtained in 1995-1996 from 13 centres in England and Wales (Brown, Amyes and Thomson [60] and unpublished results).

production has been attributed to changes in penicillinbinding proteins [63].

The most important $\beta$-lactamase in $H$. influenzae is TEM-1, which is found in $c$. $80 \%$ of $\beta$-lactamasepositive isolates $[61,62,64]$. This accounts for the present susceptibility of these organisms to $\beta$-lactam$\beta$-lactamase inhibitor combinations and cephalosporins. A second $\beta$-lactamase, ROB- 1 , has also been detected in $H$. influenzae. Although less numerous than TEM-1, ROB-1 has been found in up to $8 \%$ of isolates in some studies [61, 65]. Although not closely related, DNA sequence analysis has demonstrated that both ROB-1 and TEM-1 belong to Bush group 2b, Ambler class A enzymes [66]. Both TEM-1 and ROB1 are plasmid-mediated and transferable. Until recently, these were the only $\beta$-lactamases that had been described in $H$. influenzae; however, recent evidence suggests that the situation may be more complex. First, DNA sequence analysis of TEM-1 genes in $H$. influenzae suggests that the $b a_{T E M-1}$ gene in this species may differ from its $E$. coli counterpart, and that silent amino-acid substitutions in TEM-1 have occurred [67]. The impact of these changes on the ability of TEM-variant $\beta$-lactamases to evolve in $H$. influenzae is not clear at present. Second, a completely novel $\beta$-lactamase, VAT- 1 , has also been identified recently in $H$. influenzae [68]. The significance of this enzyme is not clear at present, but it has been detected in isolates from different geographical centres in Scotland [62, 67]. The gene encoding VAT-1 has not been sequenced, but biochemical data suggest that it is a Bush class 1, Ambler class $\mathrm{C} \beta$-lactamase [66]. VAT-1 exhibits cephalosporinase activity and resistance to the $\beta$-lactamase inhibitors clavulanic acid, sulbactam and tazobactam [68].

Erythromycin has little activity against $H$. influenzae (Table 3). However, data demonstrating azithromycin activity is currently being accumulated [69]. Resistance to chloramphenicol and tetracycline has been detected, but is currently $<5 \%$ for each (Table 3 ). Resistance to chloramphenicol results either from the production of chloramphenicol acetyl transferase or impermeability $[70,71]$, while tetracycline resistance is related to energy-dependent efflux of tetracycline, although other mechanisms also exist [72]. The genes encoding chloramphenicol and tetracycline resistance are plasmid-mediated and associated with transposons [73]. Decreased susceptibility to trimethoprim results from alterations in chromosomal dihydrofolate reductase production [74], with a current trimethoprim resistance level of $9.6 \%$ in the UK. Although there are a number of isolated reports of the emergence of quinolone resistance in $H$. influenzae [75], this does not appear to be a widespread phenomenon and resistance to ciprofloxacin and other quinolones remains low.

\section{Moraxella catarrhalis}

M. catarrhalis was regarded originally as a harmless commensal of the upper respiratory tract, but its role as a human pathogen has now been recognised. At present, $M$. catarrhalis remains susceptible to most antibiotics, with the exceptions of ampicillin and trimethoprim. $\beta$-Lactamase production in $M$. catarrhalis is now an almost universal phenomenon, with $>80 \%$ of isolates being $\beta$-lactamase-positive. Earlier reports indicated a much lower incidence of $\beta$ lactamase production; indeed, $\beta$-lactamases were not detected in M. catarrhalis until 1977. It is not clear if this apparent dramatic increase in the incidence of $\beta$ lactamase production represents the rapid dissemination of $\beta$-lactamase genes or reflects more sensitive detection methods. The presence of two $\beta$-lactamases (BRO-1 and BRO-2) in $M$. catarrhalis is well established [76]. Unlike most $\beta$-lactamases, the BRO enzymes form a number of different bands following isoelectric focusing, and these vary depending on the extraction method employed. Although these discrete bands have identical biochemical properties, suggesting that they are different forms of the same enzyme, interpretation of isoelectric focusing gels is difficult $[76,77]$. Whilst the differences between BRO- 1 and BRO-2 are defined, the occurrence of a third related $\beta$ lactamase, BRO-3, as a discrete enzyme and not a precursor of BRO-1 and BRO-2 is not confirmed [76, 78]. The BRO enzymes confer resistance to ampicillin, but remain susceptible to $\beta$-lactamase inhibitors [76]. Although the genes encoding the BRO enzymes are chromosomally located, transfer of BRO $\beta$-lactamases has been demonstrated, indicating that the genes may reside within conjugative transposons [79]. Resistance 
to trimethoprim in $M$. catarrhalis is almost universal although the mechanism is unknown. At present, resistance in the UK to other agents remains low (Table 3).

\section{Streptococcus pneumoniae}

Perhaps nowhere has the spectre of the post-antibiotic era been more clearly illustrated than with the development of penicillin resistance in Str. pneumoniae. Initial reports of penicillin resistance appeared in the USA in the 1960 s as isolated cases, but resistant isolates are now widespread. Reported levels of penicillin resistance in Str. pneumoniae differ widely. In Western Europe, Spain has a particular problem [80], but high levels of resistance in Eastern Europe are also of concern, as typified by Hungary with resistance levels of $>50 \%$ [81]. South Africa also represents a hot spot with high levels of resistance [82]. Changing patterns in levels of resistance are best established by follow-up studies within the same area and, whilst the levels of resistance vary with country, within most areas there has been a continued increase in the level of resistance over the last 20 years. Local factors influence the levels of resistance observed greatly and, in addition, resistance levels within the same centre vary depending on the source of the isolates (Fig. 1) [80]. The emergence of penicillin resistance can be correlated with local use of penicillin; however, clonal spread of resistant strains also occurs and export of penicillin-resistant strains from one country to another has been demonstrated $[83,84]$.

Penicillin resistance in Str. pneumoniae results from alterations in penicillin-binding proteins (PBPs). Str. pneumoniae produces five high molecular mass PBPs (1A, 1B, 2A, 2B and 2X) and one of low molecular mass (PBP3) [85]. Alterations in the high molecular mass proteins are associated with decreased susceptibility to penicillin whereas, in contrast, changes in PBP3 appear to have no role in the development of resistance. The alterations found in resistant strains appear not to have arisen by a process of mutation and selection, but through homologous recombination. Analysis of the sequences of genes encoding PBPs in sensitive strains demonstrates that they are uniform. However, in contrast, the genes found in resistant isolates have mosaic structures containing blocks of divergent DNA. Str. pneumoniae is naturally transformable and it is likely that the evolution of resistant PBP genes has occurred through natural homologous recombination with other species [85].

Resistance in Str. pneumoniae is not limited to penicillin, and resistance to other classes of antibiotics - particularly chloramphenicol, tetracycline and the macrolides - has also been rising steadily. Furthermore, the emergence of multiresistant strains has caused therapeutic dilemmas. Multiresistance in Str. pneumoniae - defined as resistance to at least three different classes of antibiotics - was first detected in South Africa in 1977. At present the level of multiresistant strains varies from $13.6 \%$ of isolates in Spain to $2.2 \%$ of isolates in the USA [86]. The mechanisms of resistance in Str. pneumoniae are well understood. Resistance to chloramphenicol results from the production of chloramphenicol acetyl transferase [87] and tetracycline resistance usually results from ribosomal protection as a result of the production of the TetM protein [88]. Reduced susceptibility to the macrolides results from methylation of ribosomal RNA [89]. Co-trimoxazole and trimethoprim resistance has been detected and probably results from the production of a resistant dihydrofolate reductase (as in $S$. aureus), but this has not been clarified. Although plasmids have been detected in Str. pneumoniae, it is thought that the dissemination of resistance genes among Str. pneumoniae may occur on conjugative transposons.

Finally, concern has also been raised over the development of resistance to other $\beta$-lactam agents,

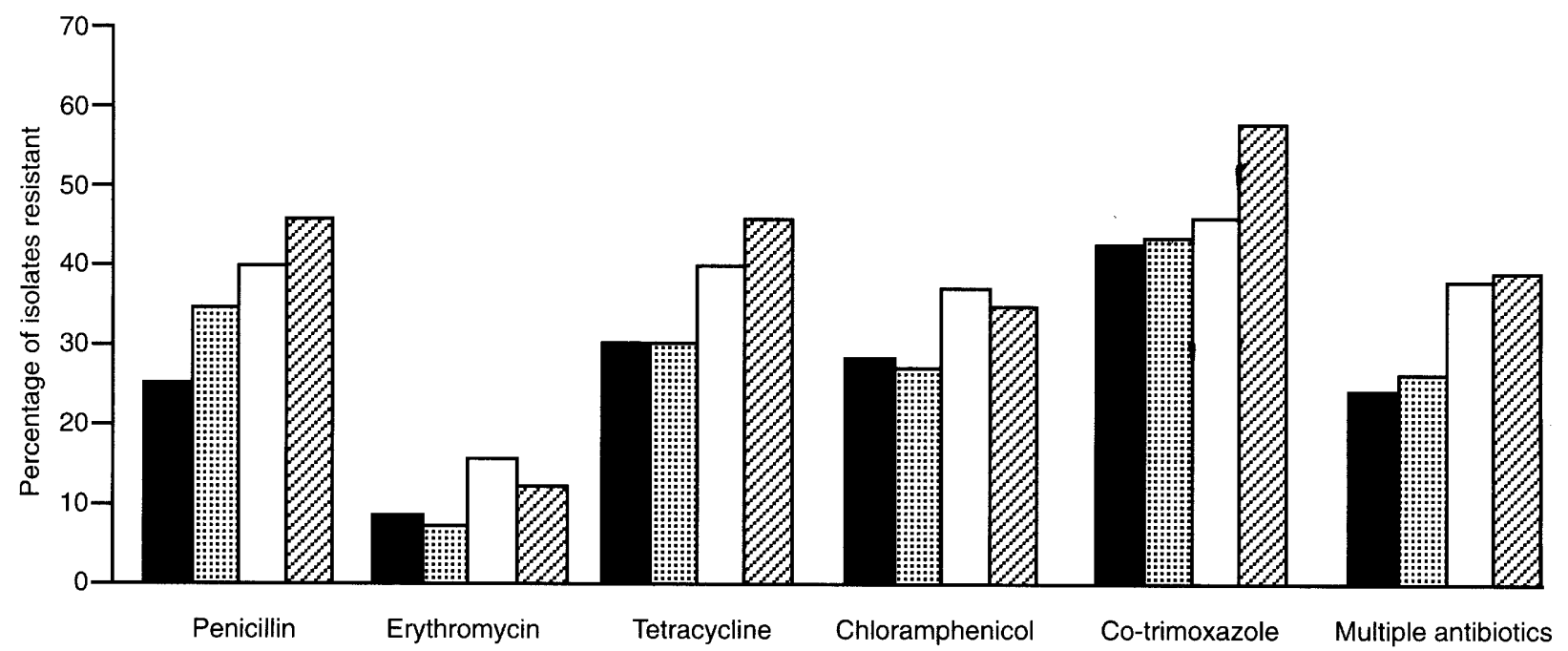

Fig. 1. Antibiotic resistance of Str. pneumoniae isolates from different sources. Data from Linares et al. [80]. 
especially the cephalosporins. In contrast to high-level resistance to penicillins, which requires modifications in four PBPs, high-level ceftriaxone resistance has been shown to result from changes in only PBPs $1 \mathrm{~A}$ and $2 \mathrm{X}$. The remaining PBPs have a natural low affinity for the cephalosporins and do not require to be modified [85].

\section{Conclusion}

Antibiotic resistance in respiratory pathogens continues to increase and is a worldwide problem. At present, a variety of options still exist for $H$. influenzae and $M$. catarrhalis. Of greater concern is the development of penicillin resistance, and indeed multiresistance, in Str. pneumoniae where there are fewer remaining options in our antibiotic armamentarium.

\section{Epidemiology of antibiotic resistance: blood and cerebrospinal fluid (CSF)}

\author{
A. P. Johnson and D. C. E. Speller \\ Antibiotic Reference Unit, Central Public Health Laboratory, \\ 61 Colindale Avenue, London NW9 $5 H T$
}

\section{Introduction}

A significant feature of medical microbiology in the 1990 s has been increasing concern about antibiotic resistance. This has lead to a heightened awareness of the importance of surveillance of resistance rates locally, nationally and internationally. In terms of national surveillance of antimicrobial resistance, one approach is for bacteria isolated in laboratories in different parts of the country to be referred to one centre where susceptibility testing may be undertaken. Such surveillance may involve testing of isolates submitted to reference laboratories for typing or other specialised investigation [90], or the testing of isolates collected specifically for surveillance purposes [18]. The former approach will usually give biased results (e.g., isolates may be referred preferentially for confirmation of particular resistance phenotypes) and may not be a reliable source of data for assessment of prevalence rates. Nonetheless, such an approach may give useful information about trends in resistance, and may be particularly valuable as an early warning system for detecting emergence of novel resistance traits. The latter approach of collecting isolates specifically for surveillance purposes may allow a more accurate assessment of prevalence rates, but the performance of such studies on a regular basis is often limited by availability of resources and staff. An alternative approach to national surveillance involves the centralised collection and analysis of susceptibility testing results from diagnostic laboratories around the country [91]. This paper reports on surveillance of antibiotic resistance in bacteria causing bacteraemia or meningitis in England and Wales, as reported to the PHLS CDSC.

\section{Collection of data}

Since 1974, diagnostic microbiology laboratories in the PHLS network, and increasing numbers of National Health Service and private hospitals in England and Wales, have reported to CDSC, on a voluntary basis, isolation of bacteria from blood or CSF. From the beginning of 1989, laboratories have also been requested to report the results of their susceptibility testing of these isolates. Results, which are reported as 'S' (susceptible), 'R' (resistant) or 'I' (intermediate), are commonly submitted as written entries on the Communicable Disease Report (CDR) Form 2 although, during the $1990 \mathrm{~s}$, variable numbers of laboratories have submitted results electronically. Laboratories contributing results to this surveillance scheme do not necessarily test the same antibiotics, although certain agents are commonly tested against particular pathogens (e.g., pneumococci are commonly tested for susceptibility to penicillin). In this report, data on four pathogens (Str. pneumoniae, S. aureus, E. coli and $K$. pneumoniae) commonly reported to CDSC as causing bacteraemia or meningitis will be reviewed. The data presented cover the 6-year period from 1989 to 1994.

\section{Str. pneumoniae}

During the period 1989-1994, there was a virtually consistent annual increase in the prevalence of resistance to penicillin among isolates of Str. pneumoniae (expressed as a percentage of the total number of isolates tested against this antibiotic), from $0.3 \%$ in 1989 to $2.5 \%$ in 1994 (Table 4) [92, 93]. The number of isolates tested for penicillin resistance each year ranged from 2667 to 3265 . For the purpose of this analysis, the term 'resistant' includes both intermediate resistance and full resistance, as the proportion of laboratories attempting to differentiate between the two levels of resistance was not known. However, in a study carried out in 1995 in which 583 pneumococci (isolated in 52 Public Health Laboratories) were collected and studied, and in which the prevalence rate for any degree of penicillin resistance was $4.9 \%$, intermediate and fully resistant organisms occurred in about equal proportions [18].

Table 4. Reported resistance to penicillin and erythromycin amongst blood and CSF isolates of Str. pneumoniae in England and Wales

\begin{tabular}{lcccccr}
\hline & \multicolumn{5}{c}{ Percentage of resistant isolates in } \\
\cline { 2 - 7 } Antibiotic & 1989 & 1990 & 1991 & 1992 & 1993 & 1994 \\
\hline Penicillin* & 0.3 & 0.5 & 0.7 & 1.9 & 1.7 & 2.5 \\
Erythromycin & 3.3 & 5.1 & 6.4 & 8.6 & 10.8 & 11.2 \\
\hline
\end{tabular}

*Includes both intermediate and full resistance. 
Of potentially greater interest was the observation that not only did resistance to erythromycin also increase between 1989 and 1994, but its prevalence was much higher than that of resistance to penicillin, rising from $3.3 \%$ in 1989 to $11.2 \%$ in 1992 (Table 4).

\section{S. aureus}

In recent years, there has been a striking increase in the occurrence of colonisation or infection of hospital patients caused by $S$. aureus strains resistant to methicillin and other antibiotics [94, 95]. In the past, the incidence of bacteraemia caused by MRSA was low, but in recent years, the proportion of $S$. aureus isolates obtained from blood or CSF that are resistant to methicillin has increased. Between 1989 and 1991, the proportion of $S$. aureus isolates obtained from blood or CSF that were resistant to methicillin remained fairly stable at c. $1.5 \%$, but increased thereafter to $8.1 \%$ by 1994. Analysis of over 2000 isolates obtained during the first half of 1995 showed a prevalence rate for methicillin resistance of $13.6 \%$ (D. C. E. Speller, unpublished observations). Interestingly, by way of contrast, the prevalence of resistance to benzyl penicillin among blood and CSF cultures of $S$. aureus remained relatively stable over this time period, fluctuating within the range $85.3-87.4 \%$, and resistance to fusidic acid also stayed relatively unchanged, varying between $1.8 \%$ and $2.4 \%$.

There has also been an increase in the prevalence of resistance to other antimicrobial agents, including erythromycin (which increased from $7.5 \%$ in 1989 to $13.3 \%$ in 1994) and ciprofloxacin (which increased from $2.9 \%$ to $16 \%$ over the same period). Both resistances appeared to be highly associated with methicillin resistance, with $90 \%$ of MRSA obtained from blood or CSF in 1995 showing these resistance phenotypes, in contrast to methicillin-sensitive $S$. aureus isolates, of which $<10 \%$ were resistant. These findings may reflect that, from 1993 onwards, the majority of MRSA isolates occurring in England and Wales comprised two epidemic strains, designated EMRSA-15 and EMRSA-16 [96], both of which are frequently resistant to erythromycin and ciprofloxacin (D. C. E. Speller and colleagues, unpublished observations)

\section{E. coli}

Analysis of the bacteraemia and meningitis database also shows ciprofloxacin resistance to be increasing in $E$. coli, albeit at a much lower rate than that seen in $S$. aureus. In $1989,0.5 \%$ of $E$. coli isolates from blood or CSF were reported as being resistant to ciprofloxacin. For the next 5 years, there was a gradual but consistent annual increase in resistance such that, by 1994 , the prevalence of ciprofloxacin resistance was $1.7 \%$. The large number of isolates for which data are available (3296 in 1989, rising to 5186 in 1994) allows meaningful statistical analysis to be performed, which shows the increase to be highly statistically significant $(\mathrm{p}<0.001$; $\chi^{2}$ for trends). Although the impact on clinical practice of this increase may be minimal at present (as $>98 \%$ of isolates remain susceptible to ciprofloxacin), the detection of a trend towards increasing resistance to such an important antibacterial agent means that it will be crucially important to continue to monitor resistance for any acceleration in the rate at which resistance is increasing. In contrast to the situation seen with ciprofloxacin, resistance to some other antibiotics did not appear to change significantly. For example, during the 6-year period, resistance to gentamicin fluctuated between 1.5 and $1.7 \%$, while the prevalence of resistance to cefotaxime was $1 \%$ in 1989 and $0.8 \%$ in 1994 (with the prevalence rates in the intervening years varying within the range $0.5-1.2 \%$ ). Resistance to ampicillin or amoxycillin was high throughout, with $54.7 \%$ of 6078 isolates and $55.8 \%$ of 6611 isolates being resistant in 1989 and 1994, respectively.

\section{K. pneumoniae}

A similar trend in patterns of antimicrobial resistance was noted in $K$. pneumoniae. Rates of resistance to ciprofloxacin increased annually, rising from $2.9 \%$ in 1989 to $6.5 \%$ in 1994 ( $p<0.001)$. The numbers of isolates reported as being tested against ciprofloxacin showed a continuous annual increase from 756 in 1989 to 1158 in 1994 . As noted with E. coli, there was no significant change in the prevalence of resistance to gentamicin $(4.1 \%$ of 1236 isolates in $1989 ; 3.8 \%$ of 1378 isolates in 1994). There was variation in the prevalence of resistance to cephalosporins from year to year. The reported prevalence of resistance to cefotaxime was $3.9 \%$ (of 618 isolates) in 1989 and $4.3 \%$ (of 670 isolates) in 1994, with the overall prevalence rates falling within the range $2.7-4.3 \%$. For ceftazidime, the rates of resistance in 1989 and 1994 were $2.7 \%$ (of 525 isolates) and $5.9 \%$ (of 819 isolates), respectively, with the overall rates falling within the range $2.7 \%-5.9 \%$.

\section{Conclusions}

Certain of the data presented here give cause for concern. With pneumococci, the high prevalence of resistance to erythromycin $(11.2 \%$ in 1994) is of probable clinical significance, as erythromycin is used to treat pneumococcal infections in patients who are allergic to penicillin or who are infected with penicillin-resistant organisms. Although the prevalence rate of $2.5 \%$ for penicillin resistance (both intermediate and full) in pneumococci in 1994 is lower than the prevalence rates of $11-36 \%$ seen in other countries [97], the upward trend described here raises the possibility that similar levels of resistance might be seen in this country in years to come.

Another area of concern is the increase in the proportion of $S$. aureus isolates that are resistant to 
methicillin. This may have implications for the empirical treatment of sepsis, as it has been shown that patients with bacteraemia caused by MRSA have a poorer outcome than patients with bacteraemia caused by methicillin-sensitive $S$. aureus, particularly if the former group do not receive appropriate therapy with an agent such as vancomycin [98]. The increasing prevalence of resistance to ciprofloxacin among staphylococci (particularly MRSA), E. coli and $K$. pneumoniae is also worrying. On the other hand, the continuing susceptibility of most isolates $(>98.2 \%)$ of $E$. coli to gentamicin shows that the picture is not entirely gloomy.

The examples presented here show the value of surveillance of antibiotic resistance based on analysis of the results of routine diagnostic testing. Such surveillance allows not only the quantitative assessment of prevalence rates for specific types of resistance, but if carried out over a prolonged period, allows changing trends in resistance to be monitored. In view of the trends towards increasing antimicrobial resistance among a number of important pathogens, it is important that surveillance of resistance continues in the future.

Epidemiology of resistance in intensive therapy units (ITUs)

\section{A. P. Fraise}

Hospital Infection Research Laboratory, City Hospital, Birmingham

\section{Infection in ITUs}

Infections in ITUs represent $20 \%$ of nosocomial infections. Units affected most commonly include burns units, neonatal units and units dealing with immunocompromised patients. The main risk factors for ITU-associated infection are invasive procedures (particularly endotracheal intubation), venous cannulation, length of stay on the ITU and the presence of renal impairment.

The results of the European Prevalence of Infection in Intensive Care (EPIC) study were reported recently [99]. In total, 4501 patients were investigated, with an overall incidence of infection of $44.8 \%$. Of the patients studied, $20.6 \%$ acquired their infection on the ITU. The main identifiable risk factors were: a length of stay of $>48 \mathrm{~h}$; a requirement for mechanical ventilation; antecedent trauma; the presence of intravenous cannulae or urinary catheter; and the use of $\mathrm{H}_{2}$ antagonists for stress ulcer prophylaxis.

\section{Antibiotic usage in ITUs}

At the City Hospital, Birmingham, the use of antimicrobial agents on the ITU has been monitored.
Although the unit is small, having only seven beds, antimicrobial usage is substantial. During Oct.-Dec. 1995, 38 patient days of ciprofloxacin (at a dose of $800 \mathrm{mg}$ b.d.) and 144 patient days of ceftazidime (at 1 g t.d.s.) were prescribed. This corresponds with an annual usage of $122 \mathrm{~g}$ of ciprofloxacin and $1.73 \mathrm{~kg}$ of ceftazidime. The financial implications of such large scale usage are considerable. In 1995, the hospital spent $£ 54715$ on antimicrobial use in the ITU. Although the ITU only accounts for just over $1 \%$ of the in-patient population, this antibiotic bill is $13 \%$ of the hospital's annual antibiotic budget. Main items included $£ 8659$ for ceftazidime and $£ 20760$ for ciprofloxacin.

\section{Antibiotic resistance in ITUs}

Given this substantial use of antibiotics, it is not surprising that ITUs are the hospital areas where most antimicrobial resistance is encountered. The EPIC study [99] identified a total of 528 ITU-acquired $S$. aureus infections, of which 272 (51\%) were caused by MRSA. Of all laboratory confirmed $S$. aureus bacteraemias, $72.4 \%$ were MRSA. Similarly, of 504 ITUacquired $P$. aeruginosa infections, 267 (65.1\%) were resistant to one or more of the following antibiotics: gentamicin, imipenem, ceftazidime, ciprofloxacin and piperacillin. In addition, $70.1 \%$ of the 335 ITUacquired coagulase-negative staphylococcal infections were caused by methicillin-resistant strains, $3.5 \%$ were vancomycin-resistant, and $9.3 \%$ were teicoplanin-resistant.

\section{Resistance in ITUs versus general hospital}

Although antimicrobial resistance is a problem in all areas of the hospital, as well as in the community, it is the ITU that is affected most severely by this problem. Isolates from the Birmingham City Hospital ITU show a much higher prevalence of resistant organisms than the rest of the hospital. Most noticeably, the prevalence of MRSA is nearly twice that in the rest of the hospital, and the proportion of gram-negative organisms resistant to ceftazidime, ciprofloxacin and gentamicin is also much higher than in general wards.

\section{Enterococci}

Several organisms known to be intrinsically resistant to a variety of antimicrobials are particular problems on ITUs and appear to be increasing in importance. Enterococci were previously thought of as harmless commensals, yet the National Nosocomial Infection Survey (NNIS) demonstrated that, between 1986 and 1989 , enterococci were the second commonest nosocomial pathogen in the USA [100]. A study of enterococcal bacteraemia [101] identified several factors that are associated with increased mortality. These included: age $>56 \mathrm{y}$; severe underlying disease; nosocomial acquisition; trauma; previous antimicrobial 
therapy; vascular or urinary catheterisation; and the presence of a surgical wound.

\section{$V R E$}

Vancomycin resistance in enterococci was first reported from London [51], but the scale of the problem in the UK has escalated so that $c .40$ centres are now affected. The difficulty in treating infections caused by VRE has been exacerbated by the concurrent development of resistance to penicillin and high levels of gentamicin. This renders these organisms untreatable with commonly available drugs. An outbreak of infection caused by an En. faecium isolate that was resistant to vancomycin, ampicillin and high-levels of gentamicin was reported from Houston in 1990 [102]. These strains also cause infection in some London hospitals, and data from the UK and the USA suggest that the number of centres affected by resistant strains, as well as the number of isolates is increasing.

\section{MRSA}

MRSA strains have caused cross-infection problems in various countries in the world. One of the first countries to experience large outbreaks with this organism was Australia, although it is also now endemic in hospitals in the USA and Europe. It is generally thought that the main mode of MRSA transmission is by hand contact, and the Hospital Infection Society has published guidelines for the control of MRSA that concentrate on procedures likely to limit the risk of hand-to-hand spread [44]. MRSA is a major problem on ITUs and this may be related to the intensity of contact with medical, nursing and paramedical staff, as the number of contacts with health care personnel has a dramatic impact on the potential for an organism to spread. Airborne spread is not generally thought to be a significant factor in the spread of MRSA, although an outbreak in the City Hospital was probably related to the proximity of an air extract from an isolation cubicle to an open window in the main ITU [103].

\section{Acinetobacter spp.}

Acinetobacter spp. are being recognised increasingly as nosocomial pathogens causing infections on ITUs. Strains are becoming more resistant to antibiotics and have been isolated from ventilators and hand wash basins. As many as $45 \%$ of trachaeostomy sites may be colonised with these organisms. Risk factors for acinetobacter infection include intravenous cannulation, antimicrobial use and admission to ITU.

\section{Induction and derepressed mutants}

Certain gram-negative organisms, such as Enterobacter, Serratia, Citrobacter and Pseudomonas spp., have the propensity to produce chromosomal $\beta$ lactamases that are inducible and active against a wide range of penicillins and cephalosporins. These $\beta$ lactamases are often termed AmpC type $\beta$-lactamases are usually chromosomal, and are inducible. Plasmidmediated enzymes with similar activity have also been described. This inducible property is reversible and can cause problems with in-vitro detection of resistance unless appropriate methods such as a disk approximation technique are used. One important aspect of these strains is that the presence of an inducible AmpC type $\beta$-lactamase is a risk factor for mutation to the derepressed state. In this state the organism produces large amounts of $\beta$-lactamase, resulting in resistance to most $\beta$-lactam antibiotics. This state tends to be irreversible.

\section{Cephalosporin use and resistance in gram- negative bacteria}

The large scale use of cephalosporins has been associated with outbreaks caused by organisms that produce cephalosporinases. A prospective case controlled study [104] examined 386 isolates from 340 patients and showed that $18.1 \%$ were resistant to extended spectrum cephalosporins (ESCs). Enterobacter spp. were a particular problem, with $31.1 \%$ exhibiting resistance to ESCs. Furthermore, there was a statistically significant association between cefotaxime, ceftazidime and piperacillin usage and resistance to ESCs ( $p=0.008,0.004,0.001$, respectively). Aminoglycoside usage seemed to protect against this effect.

\section{Quinolones and resistance}

Most quinolone resistance is caused by mutations in the gyrA gene (mainly at codon 83). Although there have been reports of plasmid-mediated resistance, these reports have not been substantiated. Several workers have demonstrated that resistance can develop following treatment, but outbreaks resulting from large-scale use seem to be rare. This may be because quinolones have been shown to have plasmid curing properties and also seem to inhibit plasmid conjugation.

\section{What can we do?}

Given the scale of the resistance problems in ITUs, and the consequent difficulty in treating infections on these units, what can be done to control the problem? It is becoming clear that the pharmaceutical industry cannot be relied upon to produce ever more powerful agents. An alternative strategy is the use of selective decontamination of the digestive tract (SDD) to reduce the risk of infection. Unfortunately, published regimens for SDD frequently include a parenteral cephalosporin and, although resistance has not been encountered in units using SDD, it has to be appreciated that extensive use of SDD may eventually worsen the problem of resistance on ITUs. Most medical microbiologists therefore recommend restrictive antibiotic policies, but the pertinent question remains: do they work? 


\section{Do antibiotic policies work?}

A study from the Fillmore Hospital, Buffalo, NY, was conducted following detection of an increased number of multiresistant strains of Ent. cloacae in the ITU between 1988 and 1990 [105]. Ceftazidime usage was restricted and the preferred antibiotic combination for infections caused by Pseudomonas spp. was piperacillin plus gentamicin. As a result, the proportion of Ent. cloacae isolates resistant to ceftazidime dropped from $46 \%$ to $25 \%$. A similar study at the Truman Medical Centre, Kansas City [106] introduced a restricted prescribing policy that required the signatures of the attending physician and an infectious disease physician. In addition, susceptibility testing was performed for certain agents only if requested by the attending physician. This resulted in a reduction in the number of ceftazidime-resistant strains of P. aeruginosa from $27 \%$ to $20 \%$.

ITUs are some of the most problematic areas in hospitals with respect to antibiotic resistance. It is likely that problems with multiresistant and intrinsically resistant organisms will increase and it is important that antibiotic prescribing is controlled to prevent an unnecessary escalation of this problem.

\section{Vancomycin resistance}

\section{J. G. M. Hastings}

Department of Clinical Microbiology, Queen Elizabeth Hospital, Edgbaston, Birmingham B17 2TH

\section{Introduction}

Although the glycopeptide antibiotic vancomycin was licensed in 1958, it has been used extensively in hospital practice only for the last 20 years. This increased use has been in response to the emergence of multiresistant gram-positive pathogens, particularly enterococci and coagulase-negative staphylococci. The use of oral vancomycin as first-line treatment of Clostridium difficile colitis has also become established practice.

Glycopeptide resistance in enterococci was first reported in the late 1980s in England and France
[51, 107]. Since these early reports, vancomycinresistant enterococci (VRE) have emerged as important nosocomial pathogens in many countries, particularly the USA [108]. These data are mirrored in the UK; in 1987 a single hospital reported the isolation of VRE, increasing to 27 hospitals in 1994 and 47 hospitals in 1995 (B. Cookson, personal communication). Glycopeptide resistance in staphylococci has been reported in $S$. haemolyticus and $S$. epidermidis. Coagulase-negative staphylococci, like enterococci, are important nosocomial pathogens causing infections, particularly infections associated with foreign bodies such as intravascular catheters, prosthetic joints and peritoneal dialysis catheters.

\section{Glycopeptide resistance in enterococci}

Resistance to glycopeptides in enterococci is phenotypically and genetically heterogeneous (Table 5). Three genotypes have been described - van $A, \operatorname{van} B$ and vanC. Strains of the vanA genotype show high-level resistance to both vancomycin and teicoplanin; resistance is inducible and is mediated by a transposon, Tn1546. Studies on the mechanism and transmission of glycopeptide resistance in enterococci have concentrated on the vanA genotype and form the basis for much of the work described below.

\section{Epidemiology}

VRE have affected principally larger hospitals, particularly tertiary referral centres and teaching hospitals [110]. In the UK, most reports of VRE outbreaks have centred on renal, oncology and haematology wards, reflecting the high levels of vancomycin usage on these units. Case-control studies have identifed a number of patient risk factors for acquiring VRE; these include severe illness with prolonged hospital stay, multiple antibiotic usage (particularly that involving cephalosporins), proximity to a colonised or infected patient, and previous treatment with vancomycin [111, 112]. The use of oral vancomycin has been associated with the isolation of both VRE and vancomycin-dependent enterococci (see below).

Epidemiological studies by pulsed-field gel electrophoresis (PFGE) of chromosomal DNA have provided

Table 5. Relationship between genotype and phenotype for vancomycin-resistant Enterococcus spp.

\begin{tabular}{llll}
\hline & & Genotype and associated phenotypic characteristics \\
\cline { 2 - 3 } Property & vanA & vanB & vanC \\
\hline Vancomycin susceptibility & High-level resistance & High- or low-level resistance & Low-level resistance \\
Teicoplanin susceptibility & Resistant & Sensitive & Sensitive \\
Expression of resistance & Inducible & Inducible & Constitutive \\
Resistance gene location & Plasmid & Chromosome & Chromosome \\
Species showing each genotype & En. faecium & En. faecium & En. gallinarum \\
& En. faecalis & En. faecalis & En. casselifavus \\
& En. avium & & En. flavescens \\
& En. durans & & \\
\end{tabular}

${ }^{*}$ Plasmid-mediated transferable $v a n B$ resistance has been described recently [109]. 
valuable information on the epidemiology and spread of VRE in hospitals [113]. Outbreaks have involved multiple strains, indicating horizontal transfer via either plasmids or transposons. However inter- and intra-hospital spread of VRE strains with identical PFGE profiles have also been observed, thereby indicating clonal transmission [109, 113]. A small initial outbreak involving a single strain of En. faecium of $v a n B$ genotype was experienced at the Queen Elizabeth Hospital, followed 12 months later by a much larger outbreak involving multiple strains, all carrying the van $B$ resistance gene [109]. There is some evidence for food and animal sources of VRE, but the principal problem probably now lies in hospitals with endemic VRE [114].

Environmental contamination with VRE is found frequently in units during outbreaks. The relative resistance of enterococci to drying and decontamination regimens increases the problems of controlling spread of this organism within the hospital environment. In response to the increasing problem of VRE in the USA, the Hospital Infection Control Practices Advisory Committee has provided guidelines for the control of VRE [115]. These include advice on surveillance methods and on prevention of spread by various control of infection methods.

\section{Biochemical basis of glycopeptide resistance}

Glycopeptide antibiotics inhibit cell-wall synthesis by complexing with the D-alanine:D-alanine (d-Ala:d-Ala) residues of the pentapeptide side chain of peptidoglycan precursors. This prevents the transfer of the precursors into the peptidoglycan molecule by transglycosidases. The conservation of the d-Ala terminal sequence in peptidoglycan from many bacterial species led to the conclusion that glycopeptide resistance relating to changes in target site would be unlikely to arise.

vanA genotype. $\operatorname{Tn} 1546$ was detected originally on a plasmid from a strain of En. faecium [116]. It was shown to carry the genes responsible for glycopeptide resistance - vanR and vanS are important in regulation of vancomycin resistant genes; vanH and vanA are responsible for the synthesis of the peptide d-Ala:dlactate (see below); van $X$ and $\operatorname{van} Y$ are responsible for hydrolysis of peptidoglycan precursors; vanY and vanZ (function unknown) are not essential for expression of glycopeptide resistance [117].

Glycopeptide-resistant enterococci synthesise peptidoglycan precursors with pentapeptide side chains terminating in d-Ala:d-Lac rather than d-Ala:d-Ala [118]. Vancomycin and teicoplanin bind poorly to dAla:d-Lac terminal sequences. The vanA gene codes for an enzyme VanA, a ligase similar to the d-Ala ligase of glycopeptide-sensitive strains but which catalyses the synthesis of d-Ala:d-Lac depsipeptide [117]. The latter then replaces d-Ala:d-Ala in the pentapeptide precursors of peptidoglycan. vanH encodes a dehydrogenase that synthesises d-Lac by the reduction of pyruvate. vanX codes for a dipeptidase that hydrolyses peptidoglycan precursors terminating in d-Ala, thus allowing the preferential incorporation of d-Ala:d-Lac into peptidoglycan. van $Y$ also encodes for a peptidase, but this is not essential for the expression of glycopeptide resistance.

vanB genotype. Enterococci with $v a n B$ genes show various levels of inducible resistance to vancomycin, but remain sensitive to teicoplanin. In-vitro studies show that vancomycin can induce resistance to teicoplanin in $v a n B^{+}$strains, suggesting that susceptibility to teicoplanin is related to a lack of induction of the resistance genes by this antibiotic [119]. Although the detailed mechanism of glycopeptide resistance in $v_{\text {an }} B^{+}$strains has yet to be confirmed, it is similar to the resistance mechanism described for van $A^{+}$strains; a ligase with $76 \%$ amino-acid homology to the van $A$ ligase is present, and this also synthesises the depsipeptide d-Ala:d-Lac [120]. Genes analogous to the van $Y$, van $X$ and van $Y$ genes of the vanA genotype are probably present. van $B$ resistance appears to be transferable by conjugation, and is associated with a large $(90-250-\mathrm{kb})$ element [121]. Recently, plasmidmediated transferable vanB resistance has been described [116].

vanC genotype. Three enterococcal species demonstrate intrinsic resistance to vancomycin - En. gallinarum, En. casseliflavus and En. flavescens. These species show low level resistance to vancomycin, but remain sensitive to teicoplanin. In En. gallinarum, the vanC gene has been shown to code for a ligase that synthesises the dipeptide d-Ala:d:Ser as the terminal residue of the pentapeptide precursor [122]

\section{Vancomycin-dependent enterococci (VDE)}

Recently, strains of enterococci that will grow only around vancomycin-containing disks, or on media supplemented with vancomycin, have been isolated in the UK and USA [123, 124]. VDE have been isolated from blood, urine and faeces, and appear to have pathogenic potential. VDE seem to arise in patients already colonised with VRE, and their emergence has been associated with the use of oral vancomycin [112] The mechanism of dependence is not understood clearly, but is probably caused by a defect in the normal d-Ala:d-Ala ligase of VRE. Such strains would only be able to synthesise a peptidoglycan via the inducible d-Ala:d-Lac ligase, and would therefore be dependent on the presence of vancomycin. This theory is supported by the ability of such vancomycindependent strains to grow around disks containing dAla:d-Ala. The clinical significance of VDE is unknown, but their dependence on the presence of vancomycin for growth raises problems for diagnostic laboratories. 


\section{Glycopeptide resistance in staphylococci}

Although less common, glycopeptide resistance in staphylococci probably represents a greater threat than that seen in enterococci. As with enterococci, there appear to be a number of different phenotypes and these are seen more often in $S$. epidermidis than in $S$. haemolyticus. Most strains remain sensitive to vancomycin (MIC $\leqslant 4 \mathrm{mg} / \mathrm{L}$ ), but show high level resistance to teicoplanin (MIC 8 or $<128 \mathrm{mg} / \mathrm{L}$ ). The mechanism of glycopeptide resistance in these strains has not been elucidated clearly. Teicoplanin-resistant isolates have been shown to have a thicker cell wall, and often have an altered colonial morphology [125-127]. In some isolates, a $39-\mathrm{kDa}$ protein has been isolated, but this shows no homology with the vanA ligase of glycopeptide-resistant enterococci [126]. Furthermore, the pentapeptide peptidoglycan precursors of teicoplanin-resistant strains terminate in d-Ala:d-Ala residues [128].

Glycopeptide resistance in $S$. aureus has not been described, apart from a single report of a teicoplaninresistant strain (MIC $8 \mathrm{mg} / \mathrm{L}$ ) which emerged during long-term treatment with teicoplanin for bacterial endocarditis [129]. However, transfer by conjugation of the vanA gene complex from enterococci to $S$. aureus has been successful in vitro, although this resistance was lost in the absence of selective pressure [130]. This raises the spectre of in-vivo transfer of glycopeptide resistance from enterococci to staphylococci; the possibility of this occurring is supported by the homology observed between some enterococcal and staphylococcal genes, including those coding for $\beta$-lactamase and high-level resistance to gentamicin.

\section{Resistance to carbapenems}

P. M. Hawkey

Department of Microbiology, University of Leeds, Leeds LS2 gJT

$\beta$-Lactam antibiotics are amongst the oldest classes of antimicrobial agents and are the most widely used. However, resistance by various mechanisms has dogged their use since the first dramatic demonstrations of the clinical use of penicillin in 1940 [131]. It was in response to the proliferation of both plasmid- and chromosomally mediated $\beta$-lactamases that the carbapenem series of antibiotics was developed. They are differentiated from conventional penicillins by the lack of a sulphur atom in the 5-membered ring and a double bond between positions 2 and 3. They have a broad spectrum of activity that encompasses gram-positive, gram-negative and anaerobic bacteria. They have extremely good stability to all of the commonly encountered plasmid-mediated $\beta$-lactamases (e.g., TEM, SHV, OXA, PSE), gram-positive $\beta$-lactamases and the AmpC-type enzymes from bacteria such as Enterobacter, Citrobacter and Pseudomonas spp.
Although some agents, such as imipenem, are potent inducers of this last group of enzymes, their stability ensures that they retain clinically useful activity. In Europe, imipenem is the most familiar carbapenem, although meropenem, with its improved stability to the mamalian enzyme dehydropeptidase I which degrades imipenem and requires the co-administration of cilastatin, is used increasingly. In other countries, such as Japan, panipenem and biapenem are also in clinical use. When considering the resistance profiles of these different agents, there is considerable cross-resistance between them.

When introduced, there was a great hope that a class of antimicrobial agents had been developed that would be immune from major resistance problems. Thus it was stated in 1986: 'This review will consider the reasons why imipenem appears to be more successful than other $\beta$-lactams in overcoming resistance in gram-negative rods' [132].

Resistance to carbapenems can arise from any one, or more, of three mechanisms: (i) insensitivity of the target site, penicillin-binding proteins (PBPs) to inhibition; (ii) impermeability of the cell to carbapenems and (iii) hydrolytic enzymes that degrade carbapenems (carbapenemases).

Insensitivity of the target PBPs to carbapenems is probably the most frequent mechanism of resistance encountered in Acinetobacter spp. [133] and has also been reported in $P$. aeruginosa. There is a complex interplay between permeability and PBP mutations which has not been well worked out in Acinetobacter spp. as yet [134]. Recently, two strains of $P r$. mirabilis, isolated from blood cultures of two patients who were treatment failures with imipenem, were shown to have decreased amounts of PBP1A, with one strain also showing decreased affinity of imipenem for PBP2 [135]. Alterations in PBPs have also been ascribed as the cause of imipenem resistance in Rhodococcus equi [136].

One of the best known examples of impermeability conferring resistance to imipenem is the loss of the D2 porin by mutants of $P$. aeruginosa, thereby preventing the uptake of imipenem. Shortly after the start of the widespread clinical use of imipenem, reports began to appear of $P$. aeruginosa isolates with a raised MIC in up to $25 \%$ of patients treated with imipenem [137]. Subsequent investigations revealed that a marked decrease in amounts of a specific outer membrane protein (OMP) - OprD2 (now known as OprD) - was associated with resistance [138]. OprD facilitates the transport of basic amino acids into the bacterial cell and, as carbapenems have a positively charged group in the side chain attached to the penem nucleus, the structural similarity explains the mechanism of resistance [139]. The induction or derepression of the chromosomal $\beta$-lactamase, although weak, is 
also as important as the mutation in the porin gene in conferring clinically significant resistance to imipenem [140]. Further evidence for the role of these $\beta$ lactamases in contributing to imipenem resistance is provided by the four-fold increase in susceptibility of $P$. aeruginosa strains treated with BRL42715, a powerful inhibitor of these $\beta$-lactamases [141]. Resistance to meropenem in $P$. aeruginosa may be associated more closely with 'intrinsic' resistance to $\beta$ lactams (some form of combination of impermeability and efflux) rather than OprD loss [142]. Differences in permeability were thought to account for the widely differing susceptibilities of three strains of Bacteroides fragilis (TAL3636, QMCN3 and QMCN4) known to produce three closely related carbapenemases. However, it appears that the susceptibility differences are caused by variations in enzyme expression [143]. There are, however, also reports of reduced susceptibility to imipenem in $B$. fragilis in the absence of $\beta$ lactamase activity [144].

The occurrence of $\beta$-lactamases capable of hydrolysing carbapenems is a comparatively new and increasingly significant phenomenon. Until recently, it was thought that only metallo- $\beta$-lactamases were capable of hydrolysing carbapenems and that no serine activity site carbapenemases existed [145]. Reference to the latest version of the 'Bush' functional classification of $\beta$-lactamases reveals the group $2 \mathrm{f}$ enzymes which are Ambler Class-A serine $\beta$-lactamases [146]. These are chromosomal $\beta$-lactamases (IMI-1, SME-1 and NMCA) found rarely in isolates of Ser marcescens and Ent. cloacae [147-149]. They are inhibited by clavulanate and, interestingly, SME-1 was isolated in 1982 from the UK before the widespread use of imipenem [147]. SME-1 was initially thought to be a metallo-enzyme because of its apparent inhibition by EDTA; however, this proved to be incorrect after further study [148]. The DNA sequence is closest to NMC-A. A transferable Class-A carbapenemase has been reported from $A$. baumanii strain $6 \mathrm{~B} 92$, isolated in 1985 from the blood culture of a patient in the Edinburgh Royal Infirmary [29]. The enzyme was designated ARI-1, with a pI value of 6.65 , and was encoded on a plasmid of c. $45 \mathrm{~kb}$, but this plasmid transferred only to $A$. junii at $25^{\circ} \mathrm{C}$.

By far the largest group of carbapenemases belong to the zinc-dependent metallo-enzymes (Ambler ClassB), reviewed in detail by Payne [150]. The chromosomal enzyme found in Bacillus cereus is the only such enzyme to undergo X-ray crystallography. This enzyme is capable of binding two zinc ions and is surrounded by two histidine residues, which are probably the true ligands, together with a cysteine residue [151]. The zinc ion is thought to bind a water molecule, which then results in the hydrolysis of the carbonyl group of the $\beta$-lactam ring. The zincdependent carbapenemase, L1, found in St. maltophilia is probably the enzyme encountered most fre- quently in clinical microbiology. The level of resistance in this bacterium to imipenem is greatly influenced by the $\mathrm{Zn}^{++}$content of sensitivity testing media [152]. The metallo- $\beta$-lactamases capable of hydrolysing carbapenemases have recently been grouped into the three functional sub-groups shown in Tables 6 and 7 .

These groups will be considered in reverse order as the most clinically relevant carbapenemases fall into group 3a. Group 3c, characterised by a very high rate of cephalosporin hydrolysis, has a sole representative which was the only example of Legionella spp. examined (L. gormanii), although other Legionella spp. probably carry similar enzymes [153]. As carbapenems are not drugs used for the treatment of infections caused by Legionella spp., these enzymes are of largely academic interest.

Group $3 \mathrm{~b}$ contains $\beta$-lactamases where the preferred substrate is carbapenems and there is much less activity against penicillins and virtually none against cephalosporins. Therefore, Bush has termed these enzymes 'true carbapenemases'. It seems that a range of enzymes can be produced by isolates and there is a need to clarify the taxonomy of these enzymes when more molecular information becomes available. At the moment, all of the examples are found in various species of Aeromonas. The most widely studied species has been $A$. hydrophila in which the CphA enzyme, also known as the A2 enzyme, has been looked at by several groups [154-156]. With a DNA probe derived from the $c p h A$ gene, it has been shown to be present in some other closely related species of Aeromonas, but only $83 \%$ of probe-positive strains express $\beta$-lactamase activity [157]. Indeed, the expression of these carbapenemases appears to be controlled by a range of mechanisms. An elegant study has demonstrated co-inducibility of the ImiS carbapenemase with two other chromosomal $\beta$-lactamases, indicating co-ordinate control of the genes [158]. It is also clear that the techniques used to identify carbapenemases are critical. Hayes and colleagues identified the enzyme ASA-I in $A$. salmonicida although this enzyme is not detected by nitrocefin as it does not hydrolyse nitrocefin as a substrate [159]. The same group has examined $A$. hydrophila by the same techniques (overlaying gels with imipenem and a $\mathrm{pH}$ indicator) and have found a carbapenemase in $A$.

Table 6. Functional subgroups of metallo- $\beta$-lactamases*

\footnotetext{
- Group 3a

Imipenem hydrolysis $<$ penicillins

Cephalosporins $<$ penicillin

- Group 3b

Imipenem hydrolysis $>$ penicillin

Very low cephalosporin hydrolysis

True 'carbapenemases'

- Group 3c

Very high cephalosporin hydrolysis
}

*According to $\mathrm{K}$. Bush (personal communication). 
Table 7. Metallo- $\beta$-lactamases - examples of strains expressing different subtypes*

\begin{tabular}{|c|c|c|c|c|c|c|}
\hline \multirow[b]{2}{*}{ Original host } & \multirow[b]{2}{*}{ Enzyme } & \multicolumn{5}{|c|}{ Relative hydrolysis of } \\
\hline & & IMP & MER & PEN & LOR & ATM \\
\hline \multicolumn{7}{|l|}{ Group 3a } \\
\hline Bac. cereus & II & 100 & 1200 & 380 & 16 & $<0.1$ \\
\hline B. fragilis $\mathrm{QMCN} 3$ & $\mathrm{Ccr} A 3$ & 100 & ND & 130 & 99 & ND \\
\hline B. fragilis $\mathrm{QMCN} 4$ & CcrA4 & 100 & ND & 69 & 26 & ND \\
\hline B. fragilis TAL 3636 & CcrA & 100 & 56 & 95 & 21 & $<0.01$ \\
\hline P. aeruginosa $\mathrm{GN} 17203$ & & 100 & 23 & 430 & 60 & $<0.6$ \\
\hline Bur. cepacia 5QIV & PCM-1 & 100 & 18 & 7.7 & 24 & $<0.6$ \\
\hline Ser. marcescens TN9106 & [MP-1 & 100 & 14 & 440 & 62 & $<2$ \\
\hline St. maltophilia ULA-511c & L1 & 100 & 60 & 1700 & 43 & $<0.01$ \\
\hline \multicolumn{7}{|l|}{ Group 3b } \\
\hline A. hydrophila AE036 & CphA & 100 & 38 & 2.1 & 0.07 & $<0.01$ \\
\hline A. hydrophila AER 19 & A2h & 100 & ND & 250 & ND & 4.7 \\
\hline A. hydrophila 872 & & 100 & ND & 1.1 & 14 & ND \\
\hline $\begin{array}{l}\text { A. salmonicida subsp. } \\
\text { achromogenes ASA111 }\end{array}$ & ASA-1 & 100 & ND & $<1$ & $<1$ & $<1$ \\
\hline A. sobria $163 \mathrm{a}$ & ImiS & 100 & 6900 & 0.33 & ND & ND \\
\hline A. sobria $14 \mathrm{M}$ & AsbM1 & 100 & 310 & 1.8 & $<0.06$ & $<0.01$ \\
\hline \multicolumn{7}{|l|}{ Group $3 \mathrm{c}$} \\
\hline L. gormanii ATCC 33297 & & 100 & ND & 140 & 1900 & $<20$ \\
\hline
\end{tabular}

IMP, imipenem; MER, meropenem; PEN, penicillin; LOR, lorfloxacin; ATM, azthreomycin.

*According to K. Bush (personal communication).

hydrophila that also does not hydrolyse nitrocefin [160]. Aeromonas spp. may act as an environmental reservoir for carbapenemases to spread to $A$. hydrophila and other gram-negative pathogens under the selective pressures of carbapenem use. The use of carbapenem monotherapy in immunocompromised patients - the largest group of patients suffering these infections - needs very careful microbiological monitoring.

The 3a group of enzymes are a very diverse group both functionally and probably genetically, but are characterised by marked penicillinase activity with a lower cephalosporinase activity. The enzyme from Bac. cereus has been described already. The L1 enzyme from St. maltophilia has been the subject of some interest and is probably found in almost all isolates of this species, although variants with very low-level expression have been described [161]. This is a chromosomal enzyme and no evidence of mobility has emerged. The nucleotide sequence has been determined and it is most closely related to other metallo- $\beta$-lactamases, but only at a very low level. It appears to be a tetrameric protein with a pI of 6.8 and is often expressed along with other $\beta$-lactamases [162]. By using a clever technique of pre-incubating with EDTA before isoelectric focusing and then overlaying the gels with either zinc salts or BRL 42715 , a potent inhibitor of serine $\beta$-lactamases, seven metallo- $\beta$-lactamases were identified by Payne et al. [163], including an enzyme with the same pI as L1 (6.8). The function and clinical significance of these enzymes is not yet clear, but requires much more investigation. An apparently species-specific and inducible chromosomal carbapenemase, designated PCM-1, has been reported from nine isolates of Burkholderia cepacia [164]. The clinical significance and distribution of this enzyme awaits further study.
Bacteroides spp., particularly $B$. fragilis, have long been recognised as producing $\beta$-lactamases, with the first carbapenemase being described in 1983 [165]. Ten metallo- $\beta$-lactamases have been reported from Bacteroides spp. [150]; however, a number of these enzymes may be identical. Bush has chosen three examples for her functional classification (Table 6). DNA sequencing has shown that $\operatorname{ccr} A$ and $c f A$ are identical $[143,166]$. The cfiA-type gene has been identified in isolates of Bacteroides spp. from three different countries [150] and is probably the most common carbapenemase in the genus. Recently, it has become clear that the genes may, at times, be silent but can be expressed when a copy of IS1186 inserts upstream of the cfiA gene [167]. The level of imipenem resistance in $B$. fragilis has been shown to relate to the level of expression of the carbapenemase for the three enzymes shown in Table 2 [143]. There is evidence of transferability of carbapenemase genes in B. fragilis [168] and a survey in Japan, where carbapenem usage is high, showed a rise from $2.0 \%$ to $5.9 \%$ in carbapenemase-producing strains over a 4year period [168]. This has clear implications for the use of carbapenems to treat anaerobic infections.

One of the most sinister developments in the story of carbapenem resistance has been the appearance in Japan of plasmid-mediated carbapenemases, initially in $P$. aeruginosa followed by a different gene appearing in Ser. marcescens with subsequent spread to $P$. aeruginosa. The first report of a plasmid-mediated carbapenemase (pI 9.0) was in a single isolate of $P$. aeruginosa (strain GN17203) on a 31-MDa plasmid which transferred only to $P$. aeruginosa and not to $E$. coli [169]. An isolate of Ser. marcescens (strain TN 9106) derived from a patient with a urinary tract infection in Okasaki in Japan in 1991 was found to produce a different $\beta$-lactamase which was named 
IMP-1 [170]. This enzyme has considerable homology with the $B$. fragilis TAL 3636 enzyme and Bac. cereus II. A recently published analysis of $P$. aeruginosa isolates in Japan between 1988 and 1992 reports that a plasmid-mediated $\beta$-lactamase with the characteristics of IMP-1 has been identified by another group [171]. Ominously, this gene became disseminated amongst isolates of Ser. marcescens in Japan and is encoded on a large plasmid $(120 \mathrm{~kb})$ and can be transferred to $E$. coli at a frequency of $10^{-5}$ [172]. The situation deteriorated further with the report that bla $_{I M P}$ is now disseminated amongst plasmids found in $P$. aeruginosa [173]. The molecular reason for this dissemination has become clear with the discovery that the bla $a_{I M P}$ gene is part of an integron [174]. Worse news still is that it has now been found in a strain of $K$. pneumoniae and isolates of Serratia and Pseudomonas spp. from throughout Japan [174]; spread to other countries seems inevitable.

In conclusion, carbapenems are extremely useful potent broad-spectrum $\beta$-lactam antibiotics with a number of indications for use in hospital practice. However, the very ease with which they can be used may be their downfall. Initially, it was thought that there would be very few resistance mechanisms in clinically significant bacteria. When the agents were used clinically, a wide range of genes capable of protecting bacteria from carbapenems have been selected in true Darwinian style. With the appearance of the $b l a_{I M P}$ gene we may be looking at the most effective retaliatory strike by bacteria against the ingenuity of the human mind that has produced such a useful class of antimicrobial agents as the carbapenems.

\section{Resistance mediated by inhibitor-resistant and extended-spectrum TEM and SHV $\beta$-lactamases}

\section{S. G. B. Amyes}

Department of Medical Microbiology, The Medical School, University of Edinburgh, Teviot Place, Edinburgh EH8 $9 \mathrm{AG}$

The TEM-1 $\beta$-lactamase is a Class A $\beta$-lactamase, with a serine residue as the active constituent in the catalysis that hydrolyses, and thus inactivates, penicillin. This serine residue lies at the back of the active site groove and is usually numbered 70 to fall in line with the conventional Class A $\beta$-lactamase numbering system [175]. Since it was first found in a plasmid from $E$. coli some 30 years ago, TEM-1 has become the most prevalent resistance gene in the world; it does not matter whether the survey is conducted in South Africa [176], India [177] or the UK [178]. No more than $10 \%$ of all the plasmid $\beta$-lactamases comprise the closely related TEM-2 $\beta$-lactamase $[177,178]$, which has identical biochemical properties and differs only by a substitution of lysine for glutamine at amino acid 39. Similarly, no more than $10 \%$ comprise the SHV-1 $\beta$ lactamase, which is also biochemically identical and which, although also a Class A $\beta$-lactamase, differs in structure from TEM-1 by approximately $35 \%$.

The reason why the TEM-1 $\beta$-lactamase is so widespread is not clear. It must be the $\beta$-lactamase molecule that can best bind and hydrolyse the most common $\beta$-lactams in clinical use, the aminopenicillins. Conventional assay techniques cannot distinguish between the hydrolysis of ampicillin by TEM-1, TEM2 and SHV-1, but the TEM-1 enzyme may have a slight advantage. In the clinical situation, this would be translated into dominance of the gene. It is also true that many TEM- $1 \beta$-lactamase genes are located on the highly successful class II transposon Tn3, and this has promoted its spread. Both TEM-2 and SHV-1 $\beta$-lactamase genes have been found on efficient transposons, but our capability to distinguish differences in transposition rate is even less discriminatory than our ability to detect changes in biochemical efficiency, and genes are not distributed nearly so widely.

The TEM-1 $\beta$-lactamase is probably not derived from a single gene, but from different gene families that differ from one another by nucleotide differences that give silent mutations which are not shown up by amino-acid changes [179]. This conclusion has been reached from studies of its mutants as there have not been enough studies that have sequenced sufficient TEM-1 $\beta$-lactamase genes to demonstrate this directly. Certainly, it would be expected that a gene as widely disseminated as the TEM- $1 \beta$-lactamase gene would acquire some silent mutations, if not some amino-acid substitutions, that do not affect activity. Perhaps significantly, the $b_{T E M-1}$ gene has been transposed into $H$. influenzae and analysis of its sequence has shown that, in Scotland at least, the gene has mutated and two amino-acid substitutions have occurred sufficiently far from the active site to have no apparent effect on catalysis. These mutations may simply have been the price paid for carriage of the gene in $H$. influenzae [66].

The wide dissemination of the TEM-1 $\beta$-lactamase has dominated the development of $\beta$-lactam drugs, particularly the later-generation cephalosporins which were confidently considered to be totally incapable of being bound to the active $\beta$-lactamase site. The shape of the active site allows ampicillin and amoxycillin to bind easily and tightly; this is facilitated by a narrowing at the entrance by the presence of a small $\alpha$-helix $(\alpha-7)$ $[180,181]$. This $\alpha$-helix is maintained by the two ionic bonds from the basic arginine residue at position 164 with the acidic residues glutamate-171 and aspartate-179. In 1982, ceftazidime was used extensively for the treatment of nosocomial infections, both for infections caused by $P$. aeruginosa (which it penetrates readily) and by the Enterobacteriaceae (which it penetrates far less readily). Therefore, when there was an outbreak of $K$. oxytoca in a neonatal unit 
in Liverpool in 1982, ceftazidime was considered to be a viable treatment option. During treatment, the causative bacteria became ceftazidime-resistant and this resistance was transferable [182]. There had been a substitution of serine for arginine at position 164 [183]. This removed the ionic bonds so that the $\alpha-7$ helix no longer hindered entry to the active site [180], thereby allowing the larger molecule of ceftazidime to bind and permitting limited hydrolysis. Fast penetrating cephalosporins, such as cefotaxime, could also now bind and were hydrolysed even more efficiently than ceftazidime, but the faster penetration of cefotaxime into the periplasmic space ensured that its improved binding to the active site was not translated into increased resistance $[184,185]$.

Perhaps the most significant feature was the fact that this mutation occurred in a Klebsiella sp. Examination of many TEM-based ESBLs suggest that this is the pivotal mutation. Its modest ability to raise the MIC of ceftazidime but not the MIC of cefotaxime, guarantees that most diagnostic laboratories fail to detect it; indeed, the presence of bacteria containing this mutation is likely to be demonstrated only by the double-disk synergy test [186] or a special E-test. It is the subsequent set of mutations that are so devastating. Usually these also occur in Klebsiella spp., most often in $K$. pneumoniae. Why this species should be so prominent in the emergence of ESBLs is unclear; perhaps the preferential codon usage in this species favours the mutations required, or it may simply be that Klebsiella spp. have an innate, albeit limited, insusceptibility to $\beta$-lactams and this may provide the 'breathing space' for these mutations to occur. In fact, remarkably few subsequent mutations occur, and they substitute amino acids at the side of the active site groove. This may improve the binding of ceftazidime, as a substitution of the basic lysine residue for the acidic glutamic acid residue at position 104 [187] or alterations of amino acids $237-240$ may change the relative orientation of the $\beta-3$ pleated sheet on the opposite side of the active site so that it increases the size of the groove and further promotes the binding of the larger cephalosporins $[180,185]$. Almost all studies that have examined these mutations have worked with cloned $\beta$-lactamase genes, but the hyper-production of the gene product in itself alters the phenotype. Therefore, to conclude what each of the mutations actually does, strains with levels of expression found in clinical bacteria should be examined to demonstrate the possible effect of subsequent mutations. The mutations at positions 104 and 240 increase ceftazidime resistance; they also increase the hydrolysis of cefotaxime, but usually insufficiently to provide clinical resistance. Clinical resistance to cefotaxime is manifest by mutations at positions 237 and 238; the former has been found only in combination with other mutations, so it is not known whether this could be an effective cefotaxime resistance mechanism in its own right. In contrast, the substitution at position 238 is found on its own, but appears quite rare (Table 8 ).

The SHV ESBLs were first found in 1982 [187]. SHV1 had undergone a single mutation that substituted serine for glycine at position 238 to form SHV-2. This is the pivotal mutation with this $\beta$-lactamase and the prevalence of SHV-2 [186] suggests that, in this enzyme, this substitution is not detrimental. The first stage in the development of extended-spectrum activity of the SHV-1 $\beta$-lactamase is the substitution of serine for glycine at this position [188]. Indeed, most of the SHV ESBLs possess this substitution; it appears essential for cefotaxime hydrolysis and is stable [189]. A more prevalent SHV-derivative appears to be SHV-5; this enzyme has an additional mutation that substitutes lysine for glutamic acid at position 240 ; this increases hydrolysis to ceftazidime considerably with the TEM molecule [189]. Enzymological data suggest that this is not so obvious in SHV, but epidemiological evidence suggests that the SHV-5 enzyme is much more prevalent than SHV-2 [190, 191], so either the enzymological data are not accurate enough or the enzyme may have a hitherto unrecognised activity; it may be better at conferring resistance to the penicillins than SHV-2. An interesting variation of this double mutation is SHV-7, which has a phenylalanine substitution for isoleucine at position 8 , and serine for arginine at position 43 [192]. It is not clear what additional benefit these two extra substitutions confer over SHV-5, particularly as they are distant from the active site. Interestingly, unlike most other ESBLs, SHV-7 was found in E. coli not Klebsiella spp., and these mutations may promote the survival of the $\beta$-lactamase in this species. SHV can also undergo an arginine-to-leucine substitution at position 205, and this change appears to work in concert with the mutations at positions 238 and 240 , with further increases in cefotaxime and ceftazidime resistance (Fig. 2).

Table 8. Effect of each mutation on the resistance function in the TEM $\beta$-lactamase

\begin{tabular}{llll}
\hline Position & Amino-acid change & Change in resistance function & Previous mutations \\
\hline 39 & Glutamine to lysine & None & After mutation at 164 \\
104 & Glutamic acid to lysine & High ceftazidime & Low ceftazidime \\
164 & Arginine to serine & High cefotaxime & After mutation at 240 \\
238 & Glycine to serine & High cefotaxime & After mutation at 164 \\
237 & Alanine to threonine & High ceftazidime & \\
240 & Glutamic acid to lysine & Little detectable change & \\
265 & Threonine to methionine & & \\
\hline
\end{tabular}




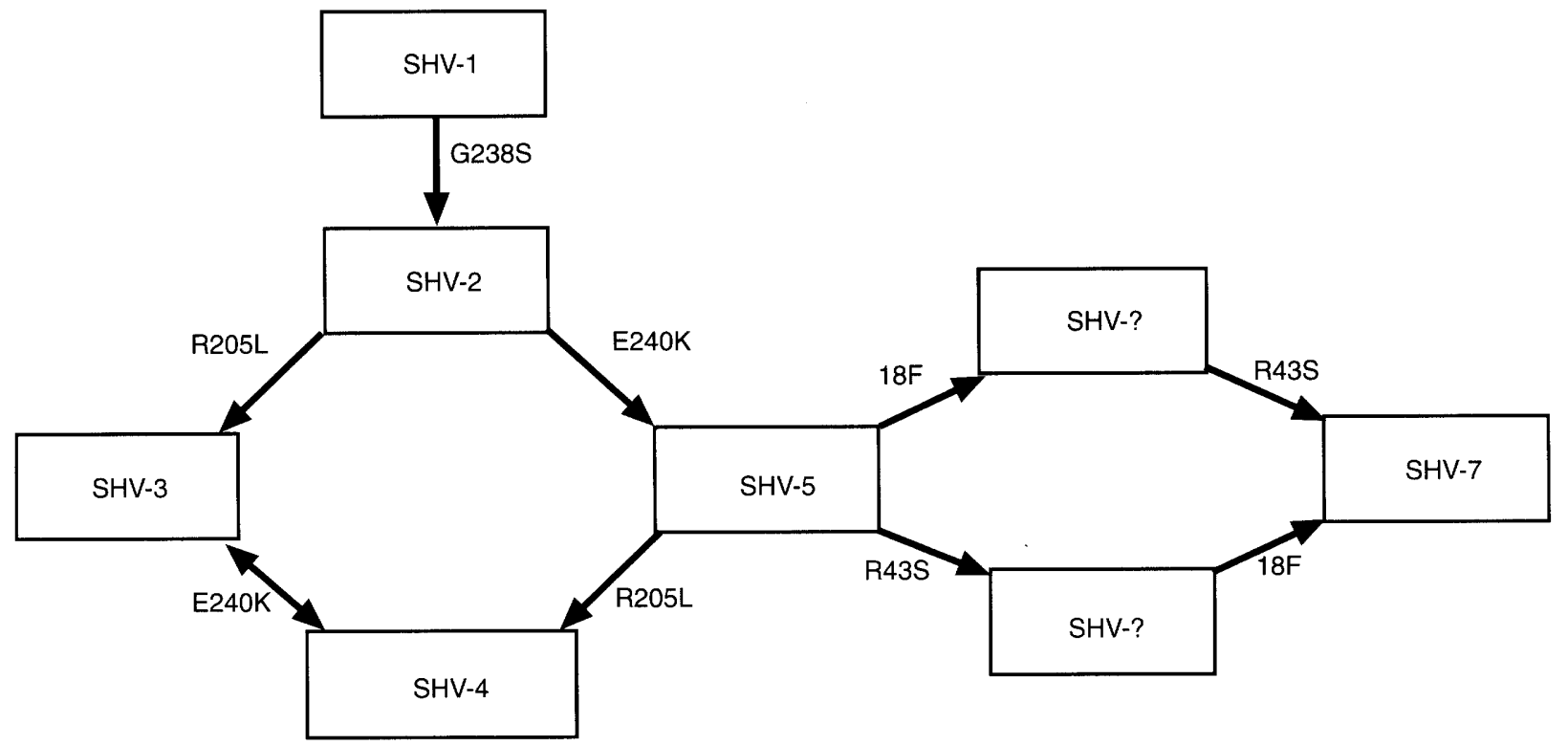

Fig. 2. Inter-relationships of the SHV-derived $\beta$-lactamases. Each arrow indicates a single amino-acid change caused by a single nucleotide change in the $\beta$-lactamase gene. Numbering of the amino-acid residues is according to the recommendations of Ambler et al. [175]: E, glutamic acid; G, glycine; K, lysine; L, leucine; R, arginine; S, serine.

Du Bois, Marriott and Amyes [193] first demonstrated that cephalosporins may not be the only selection force for ESBLs and that co-amoxiclav could select for the reversal of some of the ESBL substitutions. As extended spectrum activity is achieved by progressive substitution around the active site, there is a concomitant decrease in the capability to hydrolyse ampicillin and amoxycillin, and an increasing susceptibility to inhibition by clavulanic acid [194]. TEM-5producing bacteria challenged with co-amoxiclav undergo reverse mutations, first to TEM-10, which is more capable of binding amoxycillin and less able to bind clavulanic acid than TEM-5; thus the selective environment of both components of co-amoxiclav favours the emergence of TEM-10. Similar challenge of TEM-10 results in the emergence of TEM-12, and then TEM-1, for the same reasons [193].

In 1992, isolates of $E$. coli with reduced susceptibility to co-amoxiclav appeared first in Scotland [195] and then in France [196]. The TEM-1 $\beta$-lactamase had mutated again - under clinical conditions - and, as with the ESBLs, the mutations concentrated around a few substitutions. The mutant enzyme bound inhibitors less readily than the parent molecule and, surprisingly, this effect was less pronounced with the sulfone inhibitors, such as sulbactam and tazobactam, than with clavulanic acid. [195]. At least nine different inhibitor-resistant TEM $\beta$-lactamases have now been described [179], and there are probably more [65]. The most common alteration is the substitution of methionine at position 69 , the amino acid adjacent to the active serine-70. This is usually substituted by an aliphatic residue, which can be isoleucine, leucine or valine. So it is the loss of methionine that is important, and this may affect the orientation of small inhibitors in the active site, making their binding less secure [179]. Substitution of arginine-244 on the $\beta-4$ sheet is also important, but has been found in only two mutants (TEM-31 and TEM-32). The loss of the basic arginine residue at position 244 removes an ionic bond to the inhibitor and interferes with the inhibition process [179]. A more common mutation is the substitution of aspartate for asparagine at position 276 (found in five inhibitor-resistant TEM-type enzymes). As this mutation is never found alone, its contribution cannot be evaluated, but it is thought to alter an ionic bond with the inhibitor. Similarly, the role of the mutation at position 275 (arginine for leucine) is unknown. One of the most interesting mutations is the substitution of tryptophan-165 for arginine in the IRT-10 enzyme. Although these mutations do not confer high levels of resistance, they appear to give the strain a selective advantage in a co-amoxiclav environment, and this is supported by a recent study in a French hospital in which $8 \%$ of all urinary $E$. coli isolates were shown to possess these enzymes [197].

Are all these strains inter-related? In the inhibitorresistant TEM-type genes found so far, there appears to be some variation, particularly in nucleotides 226 , 346,436 and 672 . These cause silent mutations which, although they do not affect the amino-acid structure, reveal evolutionary diversity - the resultant enzymes are subgroups of TEM-1 (i.e., TEM-1a, TEM-1b) and TEM-2. Although the inhibitor-resistant TEM enzymes are derived from TEM-1-like enzymes, they are not all derived from the same gene. Indeed, there is evidence to suggest that different parent genes have undergone convergent evolution. Even in a single hospital, the diversity of inhibitor-resistant TEM enzymes cannot be explained by epidemic spread, which is often the case for the ESBLs. Instead, the inhibitor-resistant 
TEM enzymes appear to have evolved by independent mutation under local antibiotic selection pressure [179].

\section{Fluoroquinolone resistance: mechanisms and epidemiology}

G. S. Tillotson, I. Dorrian* and J. Blondeau $\dagger$

Bayer Corporation, West Haven, CT 06516, USA, *Bayer (UK) plc, Newbury RG14 IJA, UK and †St Paul's Hospital, Saskatoon, Saskatchewan S7M 0Z9, Canada

\section{Introduction}

Since the introduction of nalidixic acid in the early $1960 \mathrm{~s}$, a further 10 or so quinolones or fluoroquinolones have been licensed. The early agents, such as nalidixic acid and oxolinic acid, were exclusively urinary tract antibacterial agents. Later compounds, such as ciprofloxacin and ofloxacin, have a much broader clinical utility in that they can also be used to treat respiratory, blood-borne, skin and soft tissue infections, and some of these compounds are available in both oral and parenteral formulations. As a result of this better profile, the usage of fluoroquinolones now constitutes c. $11 \%$ of global antibiotic prescriptions [198]. For comparison, amoxycillin and co-amoxyclav represent over $35 \%$ of the world's prescriptions [198]. Clearly, the use of fluoroquinolones is likely to increase as bacterial resistance to the $\beta$-lactam agents, macrolides and other traditional 'first-line' agents increases. It is the purpose of this brief review to outline how the quinolones work, how bacteria have developed mechanisms of resistance to these agents, and to report on recent epidemiological surveys of fluoroquinolone resistance.

Primarily, fluoroquinolones act by interfering with the DNA replication of the bacterial cell. This is achieved by blocking the activity of specific enzymes known as topoisomerases. These enzymes are essential to the bacterial cell as they catalyse the complex process of unwinding the DNA within the cell, thereby allowing transcription to take place, and then enable re-supercoiling of the two new helices, as recognised by Cairns in 1963 [199]. Subsequently, the topoisomerases have been categorised into two groups: type I topoisomerases, topoisomerases I and III; and type II topoisomerases, DNA gyrase (topoisomerase II) and topoisomerase IV. These two types of topoisomerase differ in their mode of action: type II enzymes cleave both strands of the double helix, while type I enzymes transiently break one strand of the double helix and pass through another single strand. In 1977, Gellert [200] and Sugino et al. [201] reported that quinolones act on topoisomerase II, also known as DNA gyrase. This enzyme is composed of two A subunits (GyrA) and two B subunits (GyrB). GyrA mediates DNA strand breakage and reunion with the tyrosine residue at position 122 (Tyr-122), forming a transient phosphotyrosine linkage with a broken DNA strand. GyrB contains the ATP-binding site at the N-terminal end of the protein. The gyrA and $g y r B$ genes from a number of bacterial species have been cloned and sequenced. The gyrB and gyrA genes of Bac. subtilis, S. aureus and Mycoplasma pneumoniae are contiguous, unlike those of E. coli. A more complete review of the roles of the topoisomerases in bacterial DNA replication has been published previously [202].

In addition to their direct action on DNA gyrase, the quinolones exert other effects on viable bacteria. These effects include: inhibition of DNA synthesis by decrease in negative supertwists, reduction of decatenation of interlocked DNA circles, induction of SOS DNA repair systems and some heat shock proteins; antagonism of RNA and protein synthesis; cellular filamentation; rapid cell death.

An interesting finding has shown that alterations of the cell peptidoglycan composition occur following cell lysis by a quinolone [203]. It has been suggested that the final stages of cell death may involve newly formed murein hydrolases or autolysins. These enzymes may be involved in cell death caused by $\beta$ lactam agents [204]; indeed, the hip $Q$ mutant showed reduced killing by both quinolones and $\beta$-lactam agents [205]. To some extent, this may explain why inhibitors of RNA and protein synthesis reduce quinolone killing by virtue of the need for autolysins for quinolone-induced cell lysis.

\section{Development of resistance to the quinolones}

As always in our battle with the bacterial adversary, various means have evolved that ensure resistance to new classes of antibacterial agents. The quinolones are no different and, to date, there are two main ways in which resistance occurs. Alteration of the drug's main target site, DNA gyrase, is very common. Alternatively, a change may occur in the drug's opportunity to interact with bacterial gyrase because of reduced intracellular penetration or increasing efflux of the drug from the cell. To date, no 'quinolonase' has been reported; thus, the enzymic hydrolysis seen with other antimicrobial classes is not a problem. This may be related, in part, to the fact that quinolones are totally synthetic agents.

Each of these mechanisms seems to result from a chromosomal mutation and not from a plasmid or other genetic acquisition. To date, there have been several reports of alleged plasmid-mediated quinolone resistance in clinical isolates [206, 207]; however, none of these has been confirmed. The fact that quinolones inhibit plasmid conjugation and eliminate plasmids from host cells, combined with the dominance of susceptible wild-type $g y r^{+}$genes over resistant mutant gyr alleles, may mean that such 
plasmid-mediated resistance would be difficult to initiate and sustain [208]. There have been some instances of laboratory engineered plasmids, but their viability has been poor [209].

Alteration of DNA gyrase (topoisomerase II) may occur by changes in either of the two subunits, i.e., GyrA or B. Mutation of only GyrA can lead to quinolone resistance; an observation made in a wide range of bacterial species. Alteration of GyrA has been shown to increase the ID50 (concentration of quinolone inhibiting DNA synthesis by 50\%) 2-500fold in E. coli, $K$. pneumoniae, Ent. cloacae, $S$. aureus and $P$. aeruginosa. Genetic analysis has shown that single-point mutations in the structural genes of the A and B subunits lead to alterations in the gyrase and the concentration of quinolone required to inhibit growth (detected by an upward shift in the MIC) [202]. These alterations tend to be limited to the small region of the gene encoding amino acids 67-106 (subunit A) or 426-447 (subunit B). There are $>20$ distinct gyrA mutations reported in $E$. coli alone; other point mutations have been seen in other gramnegative and gram-positive species [210]. These changes give rise to higher levels of resistance than other mechanisms. The most potent substitutions tend to be at codons 81 and 83 ; e.g., Leu or Trp for Ser- 83 increases the ciprofloxacin MIC for $E$. coli from 0.0125 to 0.25 or $0.5 \mathrm{mg} / \mathrm{L}$ [211].

Changes in the B subunit were observed by Yamagishi et al. [212], who reported that nalC was a $g y r B$ change at position 447 , and that nalD conferred a shift at position 426. These two regions of the GyrB subunit are thought to be the ATP-binding site. The three-dimensional structure of DNA gyrase is still required in order to better understand the significance of the gyrB changes.

As with all antibiotics, quinolones must penetrate in order to exert their action. Many of the quinoloneresistant mutants have a decreased uptake mechanism; however, the hydrophobicity of each quinolone plays a role in this transportation [210]. Hydrophilic quinolones seem to traverse the outer membrane of gramnegative bacilli through aqueous-filled porin protein channels that allow direct access between the periplasmic space and the outside of the cell [210]. These proteins are expressed by the bacteria in response to environmental signals such as the osmolarity of the medium and the temperature. In the case of hydrophobic antibacterials, the outer membrane has been shown to be a barrier to drug diffusion. This property has been linked to the lipopolysaccharide (LPS) on the external surface of the outer membrane which may block drug access. It has been proposed that the more hydrophobic quinolones may promote their own diffusion by virtue of chelating magnesium which is essential for LPS stabilisation in the outer membrane [213].
The most frequent mutation associated with porin change is linked to OmpF. Other mutations have been described; thus $n f x B$, nor $B, c f x B$ and $\operatorname{mar} A$ are also associated with decreased cell penetration by quinolones. All of these mutations yield a similar resistance pattern; i.e., a slight increase in MIC (2-32-fold), which depends on each compound's hydrophobicity. In many cases, there is cross-resistance with unrelated antibiotics, such as trimethoprim, tetracycline and chloramphenicol [214].

The process of movement of a drug from within the cell to the periplasm or cell exterior is known as efflux. It is an energy-dependent process located in the inner membrane. The increased efflux of quinolones is another mechanism associated with quinolone resistance. In such mutants, Ohshita et al. [215] have demonstrated that a single point mutation at Asp-27 (for Ala) led to increased efflux. Subsequently, Kaatz and Seo [216] showed that hyper-expression of nor A may be the real cause of resistance. This mutation led to a $50 \%$ reduction in quinolone uptake [209]. Again, the overall level of resistance conferred by elevated efflux is less than that seen with gyrase changes. However, as norA is dominant over susceptible wildtype alleles, it may be feasible for this mutation to become plasmid mediated. In the laboratory setting, the nor $A$ gene of $S$. aureus has been expressed in $E$. coli [217], thereby suggesting that this transfer is possible.

It is important to realise that quinolone resistance implies cross-resistance to all quinolones, i.e., the MIC of individual quinolones will increase, but to varying degrees; the significance of this will be discussed later. In summary, gyrase changes cause greater MIC changes than other mutations.

How much impact have these resistance mechanisms had in almost 10 years of quinolone usage? It is acknowledged that the fluoroquinolones are highly active against members of the Enterobacteriaceae and respiratory gram-negative organisms such as Haemophilus, Moraxella and Neisseria spp. Of the quinolone class, only ciprofloxacin has good predictable activity against $P$. aeruginosa. In gram-positive terms, methicillin-susceptible $S$. aureus are fairly sensitive to quinolones, with Str. pneumoniae showing an intermediate level of susceptibility. Not surprisingly, with most gram-positive species and $P$. aeruginosa, the distribution of MICs tends to straddle the 'intermediate' range of values, i.e., ciprofloxacin MICs of $1.0-4.0 \mathrm{mg} / \mathrm{L}$. Clearly, with appropriate dosing of the antibiotic for the appropriate site of infection, these infecting isolates would be eradicated. It is the use (or misuse) of low dose, infrequent or short course therapy for systemic infections that has contributed to the emergence of resistant strains. The reasons for such misuse may be false economy, ignorance of the clinical situation, drug pharmacokinetics or (increas- 
ingly commonly) the use of illicit ('pirate') versions of quinolones in poorly pharmaceutically regulated areas.

It is essential that data are collected from the same centres with a similar technique over time. Table 9 shows the percentage of ciprofloxacin-susceptible strains for a range of (mainly) gram-negative pathogens isolated in three countries.

The USA is the largest consumer of antimicrobial agents, accounting for some $30 \%$ of the world's monitored consumption [198]. Virtually all of this use is through legitimate physician prescriptions; there is little or no 'black market' use of pharmaceutical agents in this country. The data shown in Table 9 [218-221] were collated from 150 hospitals and laboratories distributed throughout the contiguous states. The methods of testing used NCCLS criteria. The number of isolates examined ranged from $<10$ for Edwardsiella tarda (data not given) to $>14000$ for $E$. coli. In general terms, there have been few significant changes over the period 1992-1994. The most cause for concern occurs with $P$. aeruginosa, particularly as ciprofloxacin has provided the only oral therapeutic regimen for this problem pathogen. Conversely, of particular reassurance is the general susceptibility of the Enterobacteriaceae, while the respiratory pathogens $H$. influenzae and $M$. catarrhalis also remain highly susceptible. Interestingly, Str. pneumoniae has remained relatively susceptible to ciprofloxacin (1991, 92.5\%; $1992,92.6 \% ; 1993,92.5 \% ; 1994,89.9 \%$ [220, 221]), despite burgeoning penicillin resistance among pneumococci in the USA $(23.6 \%$ of Str. pneumoniae isolates are insusceptible to penicillin [222]). Another change causing concern has been the continued emergence of quinolone-resistant, methicillin-resistant staphylococci. Generally, these organisms are isolated in outbreak situations in closed institutions such as nursing homes [223, 224]. Monotherapy with the currently available quinolones should not form the therapeutic or prophylactic regimen for MRSA. Another gram-positive group giving cause for concern are the enterococci [225]; however, with the exception of urinary infections and a few specific systemic infections, quinolones should not be considered as first-line agents for the treatment of enterococcal infections.

Ciprofloxacin susceptibility testing has been undertaken and data collated at St Paul's Hospital, Saskatoon, Canada, since 1992 (J. Blondeau, personal communication). Additionally, susceptibilities for over 4500 isolates from 15 centres in Canada have been recorded [219]. Enterobacteriaceae appear to be fairly stable in their ciprofloxacin susceptibility; only Ser. marcescens seems to be diminishing in susceptibility (Table 9). The most prevalent species-E. coli, klebsiellae and Morganella spp.-are still highly susceptible, with $97 \%$ of Enterobacteraceae being susceptible. The degree of susceptibility among $P$. aeruginosa strains varied among the various centres; for four institutions, the rates ranged from $28 \%$ to $40 \%$.

The UK data presented in Table 9 show the ciprofloxacin susceptibility of isolates tested at 12 laboratories over an 8-year period. The isolates were from both community and hospital sources and were tested by either the disk or breakpoint (abbreviated MIC) techniques. We have previously tested the validity of these data [226]. In overall terms, the strength of these data lies in the consistency of the sites involved and the methodologies employed. Table 9 shows the levels of ciprofloxacin susceptibility observed at the time of the introduction of ciprofloxacin (1987) and the most recently collated information from the participating centres. The species showing the greatest changes are $P$. aeruginosa, $S$. aureus and Ser. marcescens, an observation substantiated by other studies [227-229].

Over the period 1991-1994, Frost et al. [230] noted that resistance to ciprofloxacin among Salmonella

Table 9. Longitudinal comparison of ciprofloxacin susceptibility data

\begin{tabular}{|c|c|c|c|c|c|c|c|c|}
\hline \multirow[b]{2}{*}{ Species } & \multicolumn{2}{|c|}{$\mathrm{USA}^{*}$} & \multicolumn{4}{|c|}{$\begin{array}{l}\text { Percentage of strains susceptible to ciprofloxacin } \\
\text { Canada }\end{array}$} & \multicolumn{2}{|c|}{ Europe $^{\S}$} \\
\hline & 1992 & 1994 & 1992 & 1995 & 1995 & 1987 & 1995 & 1990 \\
\hline E. coli & 99.4 & 99.3 & 100 & 100 & 99 & 99.8 & 99.8 & 98.7 \\
\hline Klebsiella spp. & 95.4 & 95.5 & 96 & 100 & 96 & 99.7 & 99.1 & 94.4 \\
\hline Enterobacter spp. & 93.9 & 95.1 & 100 & 100 & 97 & 99.8 & 97.9 & 98.1 \\
\hline Ser. marcescens & 83.3 & 87.4 & 100 & 98 & 92 & 99.0 & 91.8 & 83.1 \\
\hline Morganella morganii & 97.0 & 93.1 & 100 & 100 & 97 & 99.7 & 99.2 & 98.0 \\
\hline Proteus spp. & 97.6 & 95.0 & - & - & 98 & 99.7 & 99.5 & 98.6 \\
\hline$P$ aeruginosa & 81.8 & 79.0 & 98 & 89 & 79 & 98.6 & 93.1 & 84.1 \\
\hline H. influenzae & 99.8 & 99.8 & 100 & 100 & 99 & 100 & 99.5 & - \\
\hline M. catarrhalis & 100 & 100 & - & - & 99 & 100 & 100 & - \\
\hline S. aureus & - & - & 99 & 93 & 96 & 99.8 & 91.8 & 87.6 \\
\hline Str. pneumoniae & 92.6 & 89.9 & - & - & - & - & - & 一 \\
\hline
\end{tabular}

- No data available.

*Thornsberry [218]; B. Painter, personal communication.

${ }^{\dagger}$ Blondeau et al. [219].

${ }^{\ddagger}$ Tillotson and Herbert [220]; unpublished results.

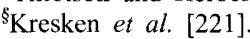


serotypes had increased from $0.3 \%$ to $2.1 \%$; in particular, serotype Hadar exhibited $39.6 \%$ resistance. Fortunately, this serotype represents $<1 \%$ of salmonellae isolated. The most prevalent serotype, Enteritidis ( $>50 \%$ of isolates) demonstrated only $0.4 \%$ resistance to ciprofloxacin. In the commonly occurring serotypes, there was a marked variation in the relationship between ciprofloxacin resistance and foreign travel, with serotypes from India and Turkey showing the highest resistance rates.

The distribution of ciprofloxacin susceptibility in Europe mirrors earlier antibiotic susceptibility surveys; i.e., quinolone resistance was higher in Southern Europe than in Northern or Central Europe (Table 10) [221]. P. aeruginosa is the most striking example of this difference, with resistance levels of $43.3 \%$ in Italy and $19 \%$ in Greece, whilst in all other countries the incidence was $<10 \%$. The authors of this multicentre survey concluded that different use of antibiotics clearly affected the degrees of resistance development. This may be associated, in part, with which quinolones were used most extensively the soonest (e.g., France with pefloxacin, while ciprofloxacin and ofloxacin were both used more frequently and earlier in Germany). This ambitious project should now be repeated as the data presented were collated in 1990.

Finally, in geographical terms, the largest population centres are in the developing nations, where there are regions in which quinolone resistance is emerging among normally very sensitive strains (e.g., Salmonella Typhi in India [231]). Ciprofloxacin resistance has been seen in $K$. pneumoniae isolates from several South American nations, including Chile (9-18\%), Mexico (21\%) and Peru (28\%) [223]. However, enteric bacteria isolated in Tanzania showed no quinolone resistance [232]; similar patterns have been seen in other Central African countries (C. F. Gilks, personal communication). One can only assume that these differences are related to the relative ease with which quinolone antibiotics can be obtained. Thus in India and some Central and South American countries, there are a multiplicity of pharmaceutical groups producing a variety of quinolones at a range of prices, while in
Africa and some other Asian countries, there is not the wholesale availability of quinolones at affordable prices.

Most of the difficulties observed with quinolone resistance have been seen with gram-positive species, including staphylococci, some streptococci, enterococci and corynebacteria. As mentioned previously, MRSA has shown the greatest propensity to become quinolone-resistant. Often this is the result of infection control problems rather than widespread chromosomal mutations among individual isolates [233]. Gramnegative species that mutate more readily include Pseudomonas spp., Campylobacter spp. [234] and a few enteric species such as the salmonellae. However, for the most prevalent pathogens (i.e., E. coli, $H$. influenzae, etc.), quinolone susceptibility is still high.

Undoubtedly, quinolone resistance is emerging among some bacterial species, often for a variety of reasons, thereby stimulating the development of new quinolones. Such agents possess superior anti-gram-positive activity, improved (or prolonged) pharmacokinetic properties and, hopefully, a comparable safety profile. Table 11 shows the MICs of four new agents: CP 99,219 or trovafloxacin [235]; OPC 17116 or grepafloxacin [236]; Du6859a [235]; and the new class, 2naphthypyridone, ABT-719 [237]. Only the latter shows significant, 'across-the-board' activity compared to ciprofloxacin. This improved activity against grampositive and anaerobic species may be a result of action on topoisomerase IV as well as DNA gyrase [238]. Several of these agents are now in Phase II and III clinical development. The outcome of this research is awaited, with the hope that the toxicity seen with previous fluoroquinolones (e.g., temafloxacin and sparfloxacin) does not become an issue. Overall, the emergence of resistance has been as anticipated and most of this resistance has occurred among hospitalised patients, perhaps reflecting horizontal crossinfection of many patients by a single resistant clone. The use of appropriate dosages and routes of administration in suitable patients, in combination with surveillance programmes, should minimise these emerging problems until new, more potent quinolones, are licensed.

Table 10. Ciprofloxacin resistance in Europe by region [221]

\begin{tabular}{lccc}
\hline & \multicolumn{3}{c}{ Percentage of resistant isolates } \\
\cline { 2 - 4 } Species & Northern & Central & Southern \\
\hline E. coli & 0.4 & 0.2 & 1.4 \\
Pr. mirabilis & 0.5 & 2.0 & 2.7 \\
Ent. cloacae & 2.5 & 0 & 2.3 \\
$K$. pneumoniae & 8.5 & 0.8 & 6.0 \\
$P$. aeruginosa & 6.9 & 6.4 & 30.6 \\
S. aureus & 5.6 & 6.2 & 23.6 \\
\hline
\end{tabular}

Northern: Belgium, Netherlands, UK.

Central: Austria, Germany, Switzerland.

Southern: France, Greece, Italy. 
Table 11. Comparison of antibacterial activity of ciprofloxacin with new compounds currently under investigation

\begin{tabular}{|c|c|c|c|c|c|}
\hline \multirow[b]{2}{*}{ Species } & \multicolumn{5}{|c|}{ MIC90 values $(\mathrm{mg} / \mathrm{L})$} \\
\hline & Cip & Trova & Grepa & Du6859a & ABT-719 \\
\hline E. coli & $<0.12$ & 0.5 & 0.12 & 0.06 & 0.008 \\
\hline Klebsiella spp. & 0.25 & 0.5 & 0.12 & 0.12 & 0.03 \\
\hline Enterobacter spp. & 0.25 & 0.12 & 0.25 & 0.06 & 0.03 \\
\hline P. aeruginosa & 0.5 & 1.0 & 4.0 & 0.5 & 0.12 \\
\hline MSSA & 1.0 & 0.03 & 0.12 & 0.03 & 0.015 \\
\hline MRSA & $>8.0$ & 1.0 & 4.0 & 1.0 & 1.0 \\
\hline En. faecalis & 2.0 & 0.25 & 4.0 & 0.25 & 0.12 \\
\hline Str. pneumoniae & 2.0 & 0.12 & 0.5 & 0.06 & 0.03 \\
\hline
\end{tabular}

Cip, ciprofloxacin; Trova, trovafloxacin; Grepa, grepafloxacin.

\section{Who or what is the source of antibiotic resistance?}

\section{E. Bergogne-Bérézin}

Bichat-Claude Bernard University Hospital, Department of Microbiology, 46 rue Henri Huchard, 75877 Paris Cedex 18, France

\section{Introduction}

Development and spread of bacterial resistance is usually attributed to overuse or misuse of antibiotics. However, antibiotic resistance is not a single phenomenon, and although many resistance mechanisms have been identified and analysed for most clinical pathogens and almost all antibiotics for clinical use, the origin and sources of antibiotic resistance have remained neglected subjects of investigation. One of the factors responsible for our current limited knowledge of the origin(s) of antibiotic resistance might be the rather limited communication between microbiologists working with clinical isolates and those who deal with industrial, agricultural or environmental microbiology. In this review, identified sources of bacterial resistance and modes of spread are analysed, as well as potential future ways to overcome resistance.

\section{Bacterial resistance in the environment}

The pre-antibiotic era. Antibiotic resistance probably has different origins in nature and must be as ancient as antibiotic synthesis [239]. Resistance genes pre-existed in nature, in soil and water, and their presence was probably related to the production of antibacterial agents, synthesised naturally in the environment by saprophytic organisms such as actinomycetes. About $10^{6} \mathrm{cfu}$ of these organisms are found per $\mathrm{g}$ of dry soil and they constitute $10-50 \%$ of all soil microorganisms. Biologically active substances are synthesised by the actinomycetes, including c. $70 \%$ of the antibiotics in use today [240, 241]. Thus, self-protection of these organisms is essential. An example of this is the aminoglycoside-modifying enzymes present in aminoglycoside producers that are active against the autogenous drugs (Table 12 summarises a few of the mechanisms of self-protection described in antibioticproducing-organisms). Chromosomal resistance genes have been characterised and cloned for many of the examples shown in Table 12. Genes encoding aminoglycoside acetyltransferase enzymes of the $\mathrm{AAC}(3)$ type are found in actinomycetes such as the lindmycinproducer Streptomyces lividus [242].

Table 12. Mechanisms of self-protection in antibiotic-producing organisms

\begin{tabular}{|c|c|c|c|}
\hline Organism & Antibiotic produced & Mechanism of resistance & Corresponding gene \\
\hline \multicolumn{4}{|l|}{ Aminoglycoside-producers } \\
\hline Streptomyces fradiae & Neomycin & $\mathrm{APH}\left(3^{\prime}\right)^{*}, \mathrm{AAC}(3)$ & $a p h, a a c^{\dagger}$ \\
\hline Streptomyces rimosus & Paromycin & $\mathrm{APH}\left(3^{\prime}\right), \mathrm{AAC}(3)$ & - \\
\hline Streptomyces lividus & Lividomycin & $\mathrm{APH}\left(3^{\prime}\right), \mathrm{AAC}(3)$ & - \\
\hline Streptomyces kanamyceticus & Kanamycin & $\mathrm{AAC}\left(6^{\prime}\right)$ & - \\
\hline \multicolumn{4}{|l|}{ Macrolide-lincosamide-producers } \\
\hline Streptomyces erythraeus & Erythromycin & $\begin{array}{l}\text { MLS } \\
\text { Ribosomal methylation (23 S) }\end{array}$ & ermE (constitutive) \\
\hline Streptomyces fradiae & Tylosin & MLS & $\operatorname{tl} A(e r m S F)$ (inducible) \\
\hline Streptomyces thermotolerans & Carbomycin & Clone specific & $\operatorname{car} B$ \\
\hline Streptomyces lincolnensis & Lincomycin & Ribosomal methylase activity & $\operatorname{clr}$ (constitutive) \\
\hline \multicolumn{4}{|l|}{ Tetracycline producers } \\
\hline Streptomyces rimosus & Tetracycline & Tetracycline efflux & tetA \\
\hline Streptomyces griseus & Tetracycline & Tetracycline efflux & tetA \\
\hline Streptomyces aureofaciens & Chlortetracycline & Tetracycline efflux & $\operatorname{tet} B$ \\
\hline \multicolumn{4}{|l|}{ Novobiocin producer } \\
\hline Streptomyces sphaeroides & Novobiocin & Altered DNA gyrase & $\operatorname{gyr} B$ (inducible) \\
\hline
\end{tabular}

This information is simplified from Cundliffe [240].

${ }^{*}$ Antibiotic-modifying enzymes: AAC, acetyltransferase; APH, phosphotransferase

${ }^{\dagger}$ Genes expressed best in $S$. lividans. 
Plasmids in nature. Extrachromosomal resistance plasmids have been recovered from bacteria isolated and stored in the pre-antibiotic era [243] and organisms producing $\beta$-lactamases have been revived from plant specimens stored in the 17th century [244]. Plasmids are known to be the major vehicles for the natural transfer of resistance genes between bacteria [244, 245]. Plasmids are particularly frequent in actinomycetes; their sizes vary from 2 to $200 \mathrm{~kb}$ with variable numbers of copies (up to 100). Plasmids in Streptomyces spp. are often implicated in resistance to the antibiotics these organisms produce [241]. As a result, soil and the natural environment constitute a huge reservoir of antibiotic resistance genes, and various potential mechanisms of resistance existed long before clinical use of antibiotics commenced 50 years ago with the advent of penicillin.

\section{Factors contributing to the development of resistance}

The advent of antibiotics in medicine and the production and use of large quantities of antibiotics have undoubtedly contributed to the selection of bacterial clones possessing resistance genes.

'Non-clinical' use of antibiotics. This plays a significant role in the spread of resistance genes. Approximately half the antimicrobial agents produced in industrialised countries are used for agricultural purposes and food supplementation for chickens, turkeys, cattle and sheep [246, 247]. Antibiotics in animals are used: (i) to restrict the spread of Salmonella spp. and other agents between animals; (ii) to treat infections in animals and for prophylaxis of infections; and (iii) to improve animal growth (antibiosupplementation). The use of avoparcin (a glycopeptide) as a growth-promoter may have played a role in the emergence and spread of glycopeptide-resistance in enterococci [248]. The veterinary use of apramycin (an aminoglycoside) may have resulted in the development of acetyltransferase (AAC(3)IV) production in commensal strains [249]. Quinolone resistance in bacteria isolated from poultry is an increasing problem resulting from use of fluoroquinolones in veterinary medicine [250]. Resistance to quinolones $(80 \%)$, tetracyclines $(47 \%)$ and kanamycin $(39 \%)$ has been observed in Campylobacter strains in Spain (F. Baquero, personal communication).

The normal intestinal flora in healthy animals. This constitutes a reservoir of resistance genes [251]. Microorganisms may transfer their plasmids to pathogenic or non-pathogenic intestinal flora and then to the intestinal flora of other individuals [252]. As the risk of infection increases when large numbers of animals or poultry are concentrated together, large quantities of antibiotics are used for prevention of infection, with increased risk of resistance selection. Thus, antibiotic resistance in animal enteric flora might be considered as a threat to human health via the food chain.

Contaminated food for animals. This has been implicated as a source of antibiotic-resistant bacteria. Even in the absence of selective pressure resulting from antibiotic use for growth promotion, animals carry large numbers of resistant strains coming from the environment and feed. Contaminated water (faecal contamination), irrigation of agricultural land by animal or human waste, and contaminated food for animals are unavoidable factors favouring plasmid carriage and transfer of resistance genes in the intestinal flora of animals [251].

Aquatic environments. These are contaminated directly by antibiotic-resistant bacteria excreted by animals or man, as well as via the practice of raw sewage discharge in waters. The assessment of water quality by identifying faecal contamination of water has identified the presence of antibiotic multiresistant $E$. coli in urban and rural drinking water sources [251, 253]. Gene transfer in the aquatic environment seems to play a significant role as a reservoir of clinical resistance genes, and it seems likely that gene transfer by transduction, transformation or conjugation may occur in water. In gram-negative bacilli such as $P$. aeruginosa and $E$. coli, conjugation is the main mechanism of transfer of R-plasmids in wastewater and sewagecontaminated samples [253].

Resistant bacteria in the human flora. The sources of resistant bacteria that can be transferred to man are multiple; transfer of antibiotic-resistant bacteria such as E. coli, Campylobacter spp. and enterococci can occur via the food chain or close contact with animals carrying resistant organisms [254]. There have been a few surveys in remote communities which have shown the natural presence of faecal plasmids coding for tetracycline and streptomycin resistance (e.g., in South Africa and in the Solomon Islands). Carriage of resistant enterobacteria in the gut of normal populations in the community has been observed [243, 251, 254]. In healthy individuals, carriage of resistant bacteria has no obvious effect, but may constitute a significant threat when infection occurs.

\section{Development of resistance in man}

The hospital environment. The development of resistance in the hospital environment is the result of multiple factors that can be summarised as follows:

1. Epidemic gram-negative bacilli are known to be inherently resistant to many antibiotics. They possess a tough outer membrane layer outside the cell wall that renders them impermeable to most antibiotic molecules so that they can be selected by antibiotic selective pressure and emerge as opportunist multiresistant pathogens. This is the case for 
P. aeruginosa, St. maltophilia and Acinetobacter spp. [255]; because of the selective conditions in the hospital environment, spread occurs between patients, particularly in intensive care units (ICUs), and these organisms can be carried by the hands of personnel and contaminate respiratory devices.

2. Emergence of resistance in pathogens during antibiotic treatment can occur by means of chromosomal mutations occurring at variable rates (e.g., $10^{-4} / \mathrm{cfu}$ in Ent. cloacae for derepression of cephalosporinase conferring resistance to thirdgeneration cephalosporins $[256] ; 10^{-6} / \mathrm{cfu}$ in $S$. aureus for fosfomycin when the drug is used in monotherapy; $10^{-7} / \mathrm{cfu}$ in $P$. aeruginosa for fluoroquinolones used to treat cystic fibrosis patients). Transfer of these resistant mutants may result in epidemics of nosocomial resistant pathogens in ICUs.

3. In-vivo transfer of plasmids coding for multiple resistance may occur into species or genera previously susceptible. Thus spread of plasmidborne ESBLs - first described in K. pneumoniae to new bacterial hosts, and the subsequent epidemics of infection, have been described extensively in the medical literature [244].

4. Spread of resistant gram-positive organisms, such as MRSA and penicillin-resistant pneumococci, is an increasing problem. Such PBP-mediated resistance mechanisms can spread by dissemination of resistant organisms in the hospital environment or by means of gene transfer (horizontal spread) [245].

In the community. An increasing prevalence of resistance has been observed in E. coli, with ampicillin resistance reaching $c .40 \%$, and spread of the TEM-1 $\beta$-lactamase gene to new hosts such as $H$. influenzae and N. gonorrhoeae. Approximately $20 \%$ of $H$. influenzae strains in the normal population are now ampicillin-resistant [254].

\section{The relationship between resistance and antibiotic usage}

Inappropriate use of antibiotics. In medical practice, drugs are often prescribed to treat either the wrong kind of infection or to treat unnecessary indications (e.g., in healthy individuals with a mild viral respiratory infection that may respond spontaneously) [257]. Inappropriate doses of oral antibiotics may achieve serum and tissue concentrations that are lower than the MICs for the infecting pathogens. Sub-MIC concentrations exert a potent selective pressure for the emergence of resistant clones that pre-exist in the bacterial population. Together with the wrong dosage, a duration of treatment that is too short also contributes to clinical failure and to emergence of drug resistance.

Antibiotic consumption. An association between changes in prevalence of resistant organisms with time and the use of antimicrobial agents is difficult to establish. Some studies have shown that antibiotic usage has contributed directly to an increased prevalence of resistance. A 7-year survey of 7385 clinical isolates in a French hospital showed changes not only in the species found but also in their antibiotic susceptibilities as a function of increased consumption of third-generation cephalosporins from $1 \mathrm{~kg}$ to $14 \mathrm{~kg} /$ year from 1980 to 1987 [258]. A study of nosocomial outbreaks of amikacin-resistant strains of Acinetobacter spp. showed a clear correlation between amikacin resistance and amikacin usage [259]. In otitis media, the increase in prevalence of $\beta$-lactamase production by $M$. catarrhalis and $H$. influenzae between 1978 and 1993 has been correlated with a substantial increase in the consumption of cephalosporins in the community [260]. Paediatric bacterial isolates are more often resistant to antibiotics than those from adults, because of more frequent infections requiring antibiotic therapy in childhood; thus an urban population carried resistant enterobacteria in $42 \%$ of cases in adults compared to $64 \%$ in children [254].

Evolution of available antibacterial drugs. As seen in Table 13, the antibacterial drugs available for clinical use in France have increased from 5 to 102 molecules within 36 years. Until the mid-1970s, the small number of available antimicrobial agents limited antibiotic usage in hospitals and in the community. Since the early 1980s, the 'explosion' of newer potent $\beta$-lactam agents (ureidopenicillins, second and third generation cephalosporins, cephamycins) and the increased usage of oral aminopenicillins, cephalosporins and macrolides, have certainly exerted a potent selective pressure on the commensal flora in hospitals and the general population. During the last 10 years, antibiotic

Table 13. Evolution of available antibacterial agents in France

\begin{tabular}{|c|c|c|}
\hline Date & Numbers of antibiotics available & Drugs available in medical practice \\
\hline 1959 & Five antibiotics & $\begin{array}{l}\text { Penicillin G, chloramphenicol, tetracycline, streptomycin, } \\
\text { erythromycin (plus sulphonamides) }\end{array}$ \\
\hline 1970 & $\begin{array}{l}\text { Five new important molecules } \\
\text { (plus a few minor ones) }\end{array}$ & Oxacillin, ampicillin, cephalothin, gentamicin, rifampicin \\
\hline 1995 & $\begin{array}{l}102 \text { molecules } \\
182 \text { presentations } \\
14 \text { antibiotic classes } \\
41 \beta \text {-lactams in } 73 \text { presentations } \\
(36 \text { new presentations since } 1987 \text { ) }\end{array}$ & $\begin{array}{l}\text { Amoxycillin ( } \pm \text { clavulanic acid), macrolides, co-trimoxazole, } \\
\text { oral cephalosporins, only one parenteral cephalosporin } \\
\text { (ceftriaxone), tetracyclines, quinolones (nalidixic acid) and } \\
\text { fluoroquinolones (ciprofloxacin, ofloxacin, sparfloxacin) }\end{array}$ \\
\hline
\end{tabular}


prescriptions in France have increased $50-80 \%$ for otitis media and sinusitis, and $70-85 \%$ for bronchitis (P. Choutet, personal communication).

\section{Ways to overcome resistance problems}

As it seems that there is no immediate way either to control dissemination of resistance genes or to restrict medical use as well as non-clinical use of antibiotics sufficiently to diminish the spread of resistance significantly, new ways to overcome resistance problems are needed. Several solutions are proposed.

1. Efforts to control antimicrobial resistance. Better surveillance systems are needed in hospitals and in the community to identify risk factors for spread of resistance and hence to define preventive strategies [257].

2. Definition of newer strategies for antibiotic therapy. This is required to avoid sub-therapeutic doses of antibacterial agents, one of the major factors responsible for development of resistance. New strategies can be based on the use of existing antibiotics.

(i) Development of new derivatives of existing drugs with prolonged half-lives, resulting in once-daily dosing and, as a result, better patient compliance and a reduced risk of selecting bacteria during periods at which drug levels are sub-MIC.

(ii) Sequential antibiotic therapy (transitional therapy) in which use of the same antibiotic, but switching from i.v. to oral administration, results in a reduced risk of acquisition of nosocomial multiresistant pathogens. This also results in lower costs, thanks to shorter hospital stays, and a reduction in nursing time. Another way would be to switch from initial i.v. therapy with a given drug to an antibiotic of another class to limit a 'one-way selective pressure' [261, 262].

(iii) Targeted antibiotic delivery with newer molecules that are highly concentrated and persistent intracellularly (intracellular quinolones or macrolides) [263] or by use of liposome-encapsulated drugs or nanoparticles that allow hydrophilic drugs to cross the lipid-permeable membranes of cells [264]. This may increase antibiotic efficacy in the many intracellular infections, while diminishing the ecological impact on the commensal flora.

3. Newer antibiotics and new perspectives in antiinfective agents. In 1940, only three genera of actinomycetes were known: Nocardia, Micromonospora and Streptomyces. Today, 80 genera have been identified, all of which have the capability to synthesise various biologically active metabolites and antibiotics of therapeutic and commercial importance. Molecular genetic analysis of genes encoding the biosynthesis of antibiotics may lead to the discovery of new antibacterial agents.

\section{Conclusion}

Man has to learn to live with resistant bacteria. A 'prudent use' of antibiotics is always recommended, but is difficult to apply. Progress in antibiotic therapy may result from newer perspectives in the control of resistance problems, but for the future there is promise in the development of new biotechnologies with drugs produced by genetic engineering. Currently, $12.5 \%$ of all new drugs are for infectious diseases. The biosynthetic attributes of bacteria, together with genetic engineering techniques and their extremely rapid growth and potent metabolic activities, permits synthesis of newer bioactive compounds. These drugs, synthesised on the basis of a better knowledge of structure-activity relationships, may provide new hope to overcome resistance problems.

\section{References}

1. Kolmer JA. Septicaemia. Ann Int Med 1934; 8: 612-631.

2. McGowan JE, Barnes MW, Finland M. Bacteremia at Boston City Hospital: occurrence and mortality during 12 selected years (1935-1972), with special reference to hospitalacquired cases. $J$ Infect Dis 1975; 132: 316-335.

3. McGowan JE. Changing etiology of nosocomial bacteremia and fungemia and other hospital-acquired infections. Rev Infect Dis 1985; 7 Suppl 3: S357-S370.

4. Mylotte JM, White D, McDermott C, Hodan C. Nosocomial bloodstream infection at a veterans hospital; 1979 to 1987. Infect Control Hosp Epidemiol 1989; 10: 455-464.

5. Murray BE. New aspects of antimicrobial resistance and the resulting therapeutic dilemmas. $J$ Infect Dis 1991; 163: 1184-1194.

6. Bergogne-Berezin E, Joly-Guillou ML. Hospital infection with Acinetobacter spp.: an increasing problem. $J$ Hosp Infect 1991; 18 Suppl B: 250-255.

7. Sirot D. Extended-spectrum plasmid-mediated $\beta$-lactamases. $J$ Antimicrob Chemother 1995; 36 Suppl A: 19-34.

8. Hibbert-Rogers LCF, Heritage J, Gascoyne-Binzi DM et al. Molecular epidemiology of ceftazidime resistant Enterobacteriaceae from patients on a paediatric oncology ward. $J$ Antimicrob Chemother 1995; 36: 65-82.

9. Shannon KP, Phillips I. A computer program for the storage and analysis of minimum inhibitory concentrations of antimicrobial agents. Binary 1990; 2: 89-95.

10. Gransden WR, Eykyn SJ, Phillips I. The computerized documentation of septicaemia. $J$ Antimicrob Chemother 1990; 25 Suppl C: $31-39$.

11. Spencer RC. Nosocomial infection in the intensive care unit: a question of surveillance. Intensive Care World 1993; 10: $173-176$

12. Koontz FP. Microbial resistance surveillance techniques. Blood cultures versus multiple body site monitoring. Diagn Microbiol Infect Dis 1992; 15 Suppl 2: 31S-35S.

13. Walder M, Karlsson E, Nilsson B. Sensitivity of 880 blood culture isolates to 24 antibiotics. Scand J Infect Dis 1994; 26: $67-75$.

14. Moller JK. Antimicrobial usage and microbial resistance in a university hospital during a seven-year period. $J$ Antimicrob Chemother 1989; 24: 983-992.

15. Emmerson AM, Enstone JE, Griffin M, Kelsey MC, Smyth ETM. The Second National Prevalence Survey of infection in hospitals - overview of the results. J Hosp Infect 1996; 32: $175-190$.

16. Geerdes HF, Ziegler D, Lode $\mathrm{H}$ et al. Septicemia in 980 patients at a university hospital in Berlin: prospective studies during 4 selected years between 1979 and 1989 . Clin. Infect Dis 1992: 15: 991-1002.

17. Eykyn SJ, Gransden WR, Phillips I. The causative organisms of septicaemia and their epidemiology. J Antimicrob Chemother 1990; 25 Suppl C:41-58.

18. Johnson AP, Speller DCE, George RC, Warner M, Domingue 
G, Efstratiou A. Prevalence of antibiotic resistance and serotypes in pneumococci in England and Wales: results of observational surveys in 1990 and 1995. BMJ 1996; 312 $1454-1456$.

19. Fomsgaard A, Hoiby N, Friis HM et al. Prevalence and antibiotic sensitivity to Danish versus other European bacterial isolates from intensive care and hematology/ oncology units. Eur J Clin Microbiol Infect Dis 1995; 14: 275-281.

20. Fass RJ, Barnishan J, Ayers LW. Emergence of bacterial resistance to imipenem and ciprofloxacin in a university hospital. J Antimicrob Chemother 1995; 36: 343-353.

21. Cometta A, Calandra T, Bille J, Glauser MP. Escherichia coli resistant to fluoroquinolones in patients with cancer neutropenia. $N$ Engl $J$ Med 1994; 300: 1240-1241.

22. Carratalá J, Fernández-Sevilla A, Tubau F, Callis M, Gudiol F. Emergence of quinolone-resistant Escherichia coli bacteremia in neutropenic patients with cancer who have received prophylactic norfloxacin. Clin Infect Dis 1995; 20: 557-560.

23. Kunova A, Trupl J, Krcmery V. Low incidence of quinolone resistance in gram-negative bacteria after five-years use of ofloxacin in prophylaxis during afebrile neutropenia. $J$ Hosp Infect 1996; 32: 155-156.

24. Liu PYF, Gur D, Hall LMC, Livermore DM. Survey of the prevalence of $\beta$-lactamases amongst 1000 Gram-negative bacilli isolated consecutively at the Royal London Hospital. $J$ Antimicrob Chemother 1992; 30: 429-447.

25. Mayer KH. The epidemiology of antibiotic resistance in hospitals. J Antimicrob Chemother 1986; 18 Suppl C: 223-233.

26. Bergogne-Bérézin E, Decré D, Joly-Guillou M-L. Opportunistic nosocomial multiply resistant bacterial infections their treatment and prevention. J Antimicrob Chemother 1993; 32 Suppl A: $39-47$.

27. Neu HC. The crisis of antibiotic resistance. Science 1992; 257: $1064-1073$.

28. Tenover FC, McGowan JE. Reasons for the emergence of antibiotic resistance. Am J Med Sci 1996; 311: 9-16.

29. Scaife W, Young H-K, Paton RH, Amyes SGB. Transferable imipenem-resistance in Acinetobacter species from a clinical source. J Antimicrob Chemother 1995; 36: 585-586.

30. O'Brien TF and the International Survey of Antibiotic Resistance Group. Resistance to antibiotics at medical centres in different parts of the world. J Antimicrob Chemother 1986; 18 Suppl C: 243-253.

31. Cookson BD. Progress with establishing and implementing standards for infection control in the UK. $J$ Hosp Infect 1995; 30 Suppl: $69-75$

32. WHO Scientific Working Group on monitoring and management of bacterial resistance to antimicrobial agents. World Health Organization, Geneva. 1994.

33. Department of Health and PHLS Working Group. The prevention and management of Clostridium difficile infection. Heywood, BAPS Health Publications Unit. 1994.

34. Report of the Public Health Laboratory Service. Incidence of surgical wound infection in England and Wales. Lancet 1960; 2: $659-663$

35. Sartor C, Edwards JR, Gaynes RP, Culver DH. National Nosocomial Infections Surveillance System. Evolution of hospital participation in the National Nosocomial Infections Surveillance System 1986 to 1993. Am J Infect Control 1995; 23: 364-368.

36. Wegelt JA, Dryer D, Haley RW. The necessity and efficiency of wound surveillance after discharge. Arch Surg 1992; 127: $77-82$.

37. Rahman A, Mackenzie D, Marples R, Cookson BD. Identification of MRSA incidents in hospitals. $J$ Hosp Infect 1995; 30: 76-78.

38. National Nosocomial Infections Surveillance (NNIS) System. Nosocomial infection rates for interhospital comparison: limitations and possible solution. Infect Control Hosp Epidemiol 1991; 12: 609-621.

39. Schaberg DR, Culver DH, Gaynes RP. Major trends in the microbial etiology of nosocomial infection. Am J Med 1991; 91: 72S-75S.

40. Panlilio AL, Culver DH, Gaynes RP et al. Methicillinresistant Staphylococcus aureus in US hospitals, 1975-1991. Infect Control Hosp Epidemiol 1992; 13: 582-586.

41. Meers PD, Ayliffe GAJ, Emmerson AM et al. Report on the
National Survey of Infection in Hospitals 1980. J Hosp Infect 1981; 2: Suppl: 1-51.

42. Olson MM, Lee JT. Continuous 10-year wound infection surveillance. Results, advantages, and unanswered questions. Arch Surg 1990; 125: 794-803.

43. Marples RR, Reith S. Methicillin-resistant Staphylococcus aureus in England and Wales. CDR Review 1992; 2: R25-29.

44. Report of a Combined Working Party of the Hospital Infection Society and the British Society of Antimicrobial Chemotherapy. Revised guidelines for the control of epidemic methicillin-resistant Staphylococcus aureus. J Hosp Infect 1990; 16: 351-377.

45. Cox RA, Mallaghan C, Conquest C, King J. Epidemic methicillin-resistant Staphylococcus aureus: controlling the spread outside hospital. J Hosp Infect 1995; 29: 107-119.

46. Cox RA, Conquest C, Mallaghan C, Marples RR. A major outbreak of methicillin-resistant Staphylococcus aureus caused by a new phage-type (EMRSA-16). J Hosp Infect 1995; 29: $87-106$.

47. Cookson BD, Peters B, Webster M, Phillips I, Rahman N, Noble W. Staff carriage of epidemic methicillin-resistant Staphylococcus aureus. J Clin Microbiol 1989; 27: $1471-1476$

48. Marples RR, Speller DCE, Cookson BD. Prevalence of mupirocin resistance in Staphylococcus aureus. J Hosp Infect 1995; 29: $153-155$

49. Spera RV, Farber BF. Multiply-resistant Enterococcus faecium. The nosocomial pathogen of the 1990s. JAMA 1992; 268: $2563-2564$

50. Anon. Nosocomial enterococci resistant to vancomycin United States 1989-1993. MMWR Morbid Mortal Wkly Rep 1993; 42: 597-599.

51. Uttley AH, George RC, Naidoo $\mathrm{J}$ et al. High-level vancomycin-resistant enterococci causing hospital infections. Epidemiol Infect 1989; 103: 173-181.

52. Wade JJ. The emergence of Enterococcus faecium resistant to glycopeptides and other standard agents - a preliminary report. J Hosp Infect 1995; 30 Suppl: 483-493.

53. Wade JJ, Desai N, Casewell MW. Hygienic hand disinfection for the removal of epidemic vancomycin-resistant Enterococcus faecium and gentamicin-resistant Enterobacter cloacae. J Hosp Infect 1991; 18: 211-218.

54. Anon. Vancomycin resistant enterococci in hospitals in the United Kingdom. Commun Dis Rep CDR Weekly 1995; 5: 281-284.

55. Murray BE. The life and times of the Enterococcus. Clin Microbiol Rev 1990; 3: 46-65.

56. Gautom RK, Stewart B, Coyle MB, Plorde JJ, Schoenknecht FD, Fritsche TR. Pulsed field gel electrophoretic analysis of vancomycin resistant enterococci (VREs) recovered from Seattle hospitals (Abstract). Am J Clin Pathol 1995; 104: 223.

57. Hospital Infection Control Practices Advisory Committee (HICPAC). Recommendations for preventing the spread of vancomycin resistance. Infect Control Hosp Epidemiol 1995; 16: $105-113$

58. Rice LB. The theoretical origin of vancomycin-resistant enterococci. Clin Microbiol Newslett 1996; 17: 24; 189-192.

59. Klare I, Heier H, Claus H, Reissbrodt R, Witte W. vanAmediated level glycopeptide resistance in Enterococcus faecium from animal husbandry. FEMS Microbiol Lett 1995; 125: $165-171$.

60. Brown S, Amyes SGB, Thomson CJ. Antibiotic resistance in Haemophilus influenzae isolated in England and Wales. 1st European Congress of Chemotherapy. Carnforth, Lancs, Parthenon Publishing. 1996. Abstract T135.

61. Scriver SR, Walmsley SL, Kau CL et al. Determination of antimicrobial susceptibilities of Canadian isolates of Haemophilus influenzae and characterization of their $\beta$-lactamases. Antimicrob Agents Chemother 1994; 38: 1678-1680.

62. Shanahan PMA, Thomson CJ, Amyes SGB. Antibiotic susceptibilities of Haemophilus influenzae in central Scotland. Clin Microbiol Infect 1: 168-174.

63. Reid AJ, Simpson IN, Harper PB, Amyes SGB. Ampicillin resistance in Haemophilus influenzae: identification of resistance mechanisms. J Antimicrob Chemother 1987; 20: 645-656.

64. Vali L, Lindsay G, Thomson CJ, Amyes SGB. $\beta$-lactamases in Haemophilus influenzae isolated in Glasgow. 94th Annual Meeting of the ASM. Washington, DC, American Society for 
Microbiology. 1994. Abstract A-72.

65. Daum RS, Murphey-Corb M, Shapira S, Dipp S. Epidemiology of ROB $\beta$-lactamase among ampicillin-resistant Haemophilus influenzae isolates in the United States. I Infect Dis 1988; 157: 450-455

66. Bush K, Jacoby GA, Medeiros AA. A functional classification scheme for $\beta$-lactamases and its correlation with molecular structure. Antimicrob Agents Chemother 1995; 39: 1211 1233.

67. Vali L, Thomson CJ, Amyes SGB. Incidence of $\beta$-lactam resistance in Haemophilus influenzae. 95th Annual Meeting of the ASM. Washington, DC, American Society for Microbiology. 1995. Abstract A-81.

68. Vali L, Thomson CJ, Amyes SGB. Haemophilus influenzae: identification of a novel $\beta$-lactamase. I Pharm Pharmacol 1994; 46: Suppl 2: 1041.

69. Retsema J, Girard A, Schelkly W et al. Spectrum and mode of action of azithromycin (CP-62, 993), a new 15-memberedring macrolide with improved potency against gram-negative organisms. Antimicrob Agents Chemother 1987; 31: 1939-1947.

70. Roberts M, Corney A, Shaw WV. Molecular characterization of three chloramphenicol acetyltransferases isolated from Haemophilus influenzae. J Bacteriol 1982; 151: 737-741.

71. Burns JL, Mendelman PM, Levy J, Stull TL, Smith AL. A permeability barrier as a mechanism of chloramphenicol resistance in Haemophilus influenzae. Antimicrob Agents Chemother 1985; 27: 46-54.

72. Speer, BS, Shoemaker NB, Salyers AA. Bacterial resistance to tetracycline: mechanisms, transfer, and clinical significance. Clin Microbiol Rev 1992; 5: 387-399.

73. Jahn G, Laufs R, Kaulfers P-M, Kolenda H. Molecular nature of two Haemophilus influenzae $\mathrm{R}$ factors containing resistances and the multiple integration of drug resistance transposons. J Bacteriol 1979; 138: 584-597.

74. de Groot R, Chaffin DO, Kuehn M, Smith AL. Trimethoprim resistance in Haemophilus influenzae is due to altered dihydrofolate reductases(s). Biochem $J$ 1991; 274: 657-662.

75. Gould IM, Forbes KJ, Gordon GS. Quinolone resistant Haemophilus influenzae. J Antimicrob Chemother 1994; 33 $187-188$.

76. Steingrube VA, Wallace RJ, Beaulieu D. A membrane-bound precursor $\beta$-lactamase in strains of Moraxella catarrhalis and Moraxella nonliquefaciens that produce periplasmic BRO-1 and BRO-2 $\beta$-lactamases. J Antimicrob Chemother 1993; 31: 237-244.

77. Simpson $\mathrm{IN}$, Plested SJ. The origin and properties of $\beta$ lactamase satellite bands seen in isoelectric focusing. J Antimicrob Chemother 1983; 12: 127-131.

78. Christensen JJ, Keiding J, Schumacher H, Bruun B. Recognition of a new Branhamella catarrhalis $\beta$-lactamase-BRO-3. $J$ Antimicrob Chemother 1991; 28: 774-775.

79. Wallace RJ, Steingrube VA, Nash DR et al. BRO $\beta$-lactamase of Branhamella catarrhalis and Moraxella subgenus Moraxella, including evidence for chromosomal $\beta$-lactamase transfer by conjugation in $B$. catarrhalis, $M$. nonliquefaciens and $M$. lacunata. Antimicrob Agents Chemother 1989; 33: 1845-1854.

80. Liñares J, Pallares R, Alonso $\mathrm{T}$ et al. Trends in antimicrobio resistance of clinical isolates of Streptococcus pneumoniae in Bellvitge hospital, Barcelona, Spain (1979-1990). Clin Infect Dis 1992; 15: 99-105.

81. Marton A. Pneumococcal antimicrobial resistance: the problem in Hungary. Clin Infect Dis 1992; 15: 106-111.

82. Koornhof HJ, Wasas A, Klugman K. Antimicrobial resistance in Streptococcus pneumoniae: a South African perspective. Clin Infect Dis 1992; 15: 84-94.

83. Reichmann $\mathrm{P}$, Varon E, Günther $\mathrm{E}$ et al. Penicillin-resistant Streptococcus pneumoniae in Germany: genetic relationship to clones from other European countries. J Med Microbiol 1995; 43: $377-385$.

84. Appelbaum PC. Antimicrobial resistance in Streptococcus pneumoniae: an overview. Clin Infect Dis 1992; 15: 77-83.

85. Spratt BG. Resistance to antibiotics mediated by target alterations. Science 1994; 264: 388-393.

86. Schutze GE, Kaplan SL, Jacobs RF. Resistant pneumococcus: a worldwide problem. Infection 1994; 22: 233-237.

87. Shaw WV. Chloramphenicol acetyltransferase: enzymology and molecular biology. CRC Crit Rev Biochem 1983; 14 $1-46$.
88. Burdett V. Purification and characterization of Tet(M), a problem that renders ribosomes resistant to tetracycline. $J$ Biol Chem 1991; 266: 2872-2877.

89. Weisblum B. Inducible resistance to macrolides, lincosamides and streptogramin type B antibiotics: the resistance phenotype, its biological diversity, and structural elements that regulate expression - a review. $J$ Antimicrob Chemother 1985; 16 Suppl A: 63-90.

90. George RC, Ball LC, Cooper PG. Antibiotic resistant pneumococci in the United Kingdom. CDR Rev 1992; 2: R37-R43.

91. George RC, Norbury PB, James D. Surveillance of antibiotic resistance in England and Wales. J Med Microbiol 1992; 36: $17-20$.

92. Aszkenasy OM, George RC, Begg NT. Pneumococcal bacteraemia and meningitis in England and Wales 1982 to 1992. Commun Dis Rep CDR Rev 1995; 5: R45-R50.

93. Anon. Antimicrobial resistance of pneumococci isolated from blood and cerebrospinal fluid, 1993 and 1994. Commun Dis Rep CDR Weekly 1995; 5: 187-188.

94. Wenzel RP, Nettleman MD, Jones RN, Pfaller MA. Methicillin-resistant Staphylococcus aureus: implications for the 1990s and effective control measures. Am J Med 1991; 91 Suppl B: 221S-227S.

95. Marples RR, Reith S. Methicillin-resistant Staphylococcus aureus in England and Wales. Commun Dis Rep CDR Rev 1992; 2: R25-29.

96. Anon. Epidemic methicillin-resistant Staphylococcus aureus. Commun Dis Rep CDR Rev 1996; 6: 197

97. Friedland IR. Treatment of pneumococcal infections in the era of increasing penicillin resistance. Curr Opin Infect Dis 1995; 8: $213-217$.

98. French GL, Cheng AFB, Ling JML, Mo P, Donnan S. Hong Kong strains of methicillin-resistant and methicillin-sensitive Staphylococcus aureus have similar virulence. J Hosp Infect 1990; 15: $117-125$.

99. Vincent JL, Bihari PJ, Suter PM et al. The prevalence of nosocomial infection in intensive care units in Europe results of the European prevalence of infection in intensivecare (EPIC) study. EPIC International Advisory Committee JAMA 1995; 274: 639-644.

100. Emori TG, Gaynes RP. An overview of nosocomial infections, including the role of the microbiology laboratory. Clin Microbiol Rev 1993; 6: 428-442.

101. Maki DG, Agger WA. Enterococcal bacteremia: clinical features, the risk of endocarditis and management. Medicine 1988; 67: 248-269.

102. Handwerger S, Raucher B, Altarac D et al. Nosocomial outbreak due to Enterococcus faecium highly resistant to vancomycin, penicillin and gentamicin. Clin Infect Dis 1993; 16: $750-755$

103. Cotterill S, Evans R, Fraise AP. An unusual source for an outbreak of methicillin-resistant Staphylococcus aureus on an intensive therapy unit. $J$ Hosp Infect 1996; 32: 207-216.

104. Jacobson KL, Cohen SH, Inciardi JF et al. The relationship between antecedent antibiotic use and resistance to extendedspectrum cephalosporins in Group I $\beta$-lactamase-producing organisms. Clin Infect Dis 1995; 21: 1107-1113.

105. Ballow $\mathrm{CH}$, Schentag JJ. Trends in antibiotic utilization and bacterial resistance. Report of the National Nosocomial Resistance Surveillance Group. Diagn Microbiol Infect Dis 1992; 15 Suppl 2: 37S-42S.

106. Bamberger DM, Dahl SL. Impact of voluntary vs enforced compliance of third-generation cephalosporin use in a teaching hospital. Arch Intern Med 1992; 152: 554-557.

107. Leclercq R, Derlot E, Duval J, Courvalin P. Plasmid-mediated resistance to vancomycin and teicoplanin in Enterococcus faecium. $N$ Engl J Med 1988; 319: 157-161.

108. Centers for Disease Control and Prevention. Nosocomial enterococci resistant to vancomycin - United States 1989-1993. Morb Mort Weekly Rep 1993; 42: 597-599.

109. Woodford N, Morrison D, Johnson AP et al. Plasmid mediated $\operatorname{VanB}$ glycopeptide resistance in enterococci. Microb Drug Res 1995; 1: 235-240.

110. Edmond MB, Ober JF, Weinbaum DL et al. Vancomycinresistant Enterococcus faecium bacteremia: risk factors for infection. Clin Infect Dis 1995; 20: 1126-1133.

111. Hastings JGM, Jolley AJ. Vancomycin resistant and dependent enterococci in a tertiary referral centre. 35th ICAAC, San 
Francisco. Washington, DC, American Society for Microbiology. 1995. Abstract.

112. Woodford N, Morrison D, Johnson AP, Briant V, George RC, Cookson B. Application of DNA probes for rRNA and VanA genes to investigation of a nosocomial cluster of vancomycinresistant enterococci. J Clin Microbiol 1993; 31: 653-658.

113. Sader HS, Pfaller MA, Tenover FC, Hollis RJ, Jones RN. Evaluation and characterization of multiresistant Enterococcus faecium from 12 US Medical Centers. J Clin Microbiol 1994; 32: $2840-2842$

114. Bates J, Jordens JZ, Griffiths DT. Farm animals as a putative reservoir for vancomycin-resistant enterococci infection in man. J Antimicrob Chemother 1994; 34: 507-516.

115. Centers for Disease Control and Prevention. United States: Federal Register. Preventing the spread of vancomycin resistance. 1994; 59: 257-263

116. Arthur M, Molinas C, Depardieu F, Courvalin P. Characterization of $\mathrm{Tn}$ 1546, a Tn3-related transposon conferring glycopeptide resistance by synthesis of depsipeptide peptidoglycan precursors in Enterococcus faecium BM4147. $J$ Bacteriol 1993; 175: 117-127.

117. Arthur M, Courvalin P. Genetics and mechanisms of glycopeptide resistance in enterococci. Antimicrob Agents Chemother 1993; 37: 1563-1571.

118. Messer J, Reynolds PE. Modified peptidoglycan precursors produced by glycopeptide-resistant enterococci. FEMS Microbiol Lett 1992; 73: 95-200.

119. Quintiliani R, Evers S, Courvalin P. The vanB gene confers various levels of self-transferable resistance to vancomycin in enterococci. J Infect Dis 1993; 167: 1220-1223.

120. Evers S, Reynolds PE, Courvalin P. Sequence of the vanB and $d d l$ genes encoding D-alanine: D-lactate and D-alanine ligases in vancomycin-resistant Enterococcus faecalis V583. Gene 1994; 140: 97-102.

121. Quintiliani R, Courvalin P. Conjugal transfer of the vancomycin resistance determinant vanB between enterococci involves the movement of large genetic elements from chromosome to chromosome. FEMS Microbiol Lett 1994; 119: $359-363$.

122. Billot-Klein D, Gutmann L, Sable S, Guittet E, van Heijenoort J. Modification of peptidoglycan precursors is a common feature of the low-level vancomycin-resistant vanB type Enterococcus D366 and of the naturally glycopeptideresistant species Lactobacillus casei, Pediococcus pentosaceus, Leuconostoc mesenteroides, and Enterococcus gallinarum. J Bacteriol 1994; 176: 2398--2405.

123. Woodford N, Johnson AP, Morrison D et al. Vancomycindependent enterococci in the United Kingdom. $J$ Antimicrob Chemother 1994; 33: 1066.

124. Fraimow HS, Jungkind DL, Lander DW, Delso DR, Dean JL. Urinary tract infection with an Enterococcus faecalis isolate that requires vancomycin for growth. Ann Intern Med 1994; 121: $22-26$

125. Biavasco F, Giovanetti E, Montanari MP, Lupidi R, Varaldo PE. Development of in-vitro resistance to glycopeptide antibiotics: assessment of staphylococci of different species. J Antimicrob Chemother 1991; 27: 71-79.

126. Daum RS, Gupta S, Sabbagh R, Milewski WM. Characterization of Staphylococcus aureus isolates with decreased susceptibility to vancomycin and teicoplanin: isolation and purification of a constitutively produced protein associated with decreased susceptibility. J Infect Dis 1992; 166: $1066-1072$.

127. Sanyal D, Greenwood D. An electronmicroscope study of glycopeptide antibiotic-resistant strains of Staphylococcus epidermidis. J Med Microbiol 1993; 39: 204-210.

128. O'Hare MD, Reynolds PE. Novel membrane proteins present in teicoplanin-resistant, vancomycin-sensitive, coagulase-negative Staphylococcus spp. J Antimicrob Chemother 1992; 30: $753-768$.

129. Kaatz GW, Seo SM, Dorman NJ, Lerner SA. Emergence of teicoplanin resistance during therapy of Staphylococcus aureus endocarditis. $J$ Infect Dis 1990; 162: 103-108.

130. Noble WC, Virani Z, Cree RGA. Co-transfer of vancomycin and other resistance genes from Enterococcus faecalis NCTC 12201 to Staphylococcus aureus. FEMS Microbiol Lett 1992; 72: $195-198$.

131. Abraham EP, Chain E. An enzyme from bacteria able to destroy penicillin. Nature 1940; 146: 837.
132. Williams RJ, Yang Y-J, Livermore DM. Mechanisms by which imipenem may overcome resistance in Gram-negative bacilli. $J$ Antimicrob Chemother 1986; 18 Suppl E: 9-13.

133. Gehrlein M, Leying H, Cullman W, Wendt S, Opferkuch W. Imipenem resistance in Acinetobacter baumanii is due to altered penicillin-binding proteins. Chemotherapy 1991; 37: 405-412.

134. Bergogne-Bérézin E, Joly-Guillou ML. Antibiotic resistance mechanisms in Acinetobacter. In: Towner KJ, BergogneBérézin E, Fewson CA (eds) The biology of Acinetobacter: taxonomy, clinical importance, molecular biology, physiology, industrial relevance. New York, Plenum Press. 1991: 83-115.

135. Neuwirth C, Síebor E, Duez J-M, Péchinot A, Kazmierczak A. Imipenem resistance in clinical isolates of Proteus mirabilis associated with alterations in penicillin-binding proteins. J Antimicrob Chemother 1995; 36: 335-342.

136. Nordmann P, Nicolas MH, Gutmann L. Penicillin-binding proteins of Rhodococcus equi: potential role in resistance to imipenem. Antimicrob Agents Chemother 1993; 37: 1406-1409.

137. Pederson SS, Pressler T, Høiby N, Bentzon MW, Cock C. Imipenem/cilastin treatment of multiresistant Pseudomonas aeruginosa lung infections in cystic fibrosis. $J$ Antimicrob Chemother 1985; 16: 629-635.

138. Buscher KH, Cullman W, Dick W, Opferkuch W. Imipenem resistance in Pseudomonas aeruginosa resulting from diminished expression of an outer membrane protein. Antimicrob Agents Chemother 1987; 31: 703-708.

139. Trias J, Nikaido H. Protein D2 channel of the Pseudomonas aeruginosa outer membrane has a binding site for basic amino acids and peptides. J Biol Chem 1990; 265: $15680-15684$

140. Livermore DM. Interplay of impermeability and chromosomal $\beta$-lactamase activity in imipenem-resistant Pseudomonas aeruginosa. Antimicrob Agents Chemother 1992; 36: 2046-2048.

141. Zhou XY, Kitzis M, Gutman L. Role of cephalosporinase in carbapenem resistance of clinical isolates of Pseudomonas aeruginosa. Antimicrob Agents Chemother 1993; 37: 387-389.

142. Chen HY, Yuan M, Livermore DM. Mechanisms of resistance to $\beta$-lactam antibiotics amongst Pseudomonas aeruginosa isolates collected in the UK in 1993. J Med Microbiol 1995; 43: 300-309.

143. Rasmussen BA, Yang Y, Jacobus N, Bush K. Contribution of enzymatic properties, cell permeability, and enzyme expression to microbiological activities of $\beta$-lactams in three Bacteroides fragilis isolates that harbor a metallo- $\beta$-lactamase gene. Antimicrob Agents Chemother 1994; 38: 2116-2120.

144. Edwards R, Greenwood D. An investigation of $\beta$-lactamases from clinical isolates of Bacteroides species. $J$ Med Microbiol 1992; 36: 89-95.

145. Livermore DM. $\beta$-lactamases in laboratory and clinical resistance. Clin Microbiol Rev 1995; 8: 557-584.

146. Bush K, Jacoby GA, Medeiros AA. A functional classification scheme for $\beta$-lactamases and its correlation with molecular structure. Antimicrob Agents Chemother 1995; 39: 1211-1233.

147. Yang Y, Wu P, Livermore DM. Biochemical characterization of a $\beta$-lactamase that hydrolyzes penems and carbapenems from two Serratia marcescens isolates. Antimicrob Agents Chemother 1990; 34: 755-758

148. Naas T, Vandel L, Soughakoff W, Livermore DM, Nordmann P. Cloning and sequence analysis of the gene for a carbapenem-hydrolyzing Class A $\beta$-lactamase, Sme-1, from Serratia marcescens S6. Antimicrob Agents Chemother 1994; 38: $1262-1270$

149. Naas T, Nordmann P. Analysis of a carbapenem-hydrolyzing class A $\beta$-lactamase from Enterobacter cloacae and of its LysR-type regulatory protein. Proc Natl Acad Sci USA 1994; 91: 7693-7697.

150. Payne DJ. Metallo- $\beta$-lactamases - a new therapeutic challenge. J Med Microbiol 1993; 39: 93-99.

151. Sutton BJ, Artymiuk PJ, Cordero-Borboa AE, Little C, Phillips DC, Waley SG. An X-ray crystallographic study of the $\beta$-lactamase II from Bacillus cereus at $0.35 \mathrm{~nm}$ resolution. Biochem J 1987; 248: 181-188.

152. Hawkey PM, Birkenhead D, Kerr KG, Newton KE, Hyde WA. Effect of divalent cations in bacteriological media on the 
susceptibility of Xanthomonas maltophilia to imipenem, with special reference to zinc ions. J Antimicrob Chemother 1993; 31: $47-55$

153. Fuji T, Sato $\mathrm{K}$, Miyata $\mathrm{K}$, Inoue $\mathrm{M}$, Mitsuhashi $\mathrm{S}$. Biochemical properties of $\beta$-lactamase produced by Legionella gormanii. Antimicrob Agents Chemother 1986; 29 925-926.

154. Shannon K, King A, Phillips I. $\beta$-Lactamases with high activity against imipenem and Sch 34343 from Aeromonas hydrophila. J Antimicrob Chemother 1986; 17: 45-50.

155. Bakken JS, Sanders CC, Clark RB, Hori M. $\beta$-Lactam resistance in Aeromonas spp. caused by inducible $\beta$ lactamases active against penicillins, cephalosporins, and carbapenems. Antimicrob Agents Chemother 1988; 32. 1314-1319.

156. Iaconis JP, Sanders CC. Purification and characterization of inducible $\beta$-lactamases in Aeromonas spp. Antimicrob Agents Chemother 1990; 34: 44-51.

157. Rossolini GM, Zanchi A, Chiesurin A, Amicosante G, Satta G, Guglielmetti P. Distribution of $c p h A$ or related carbapenemase-encoding genes and production of carbapenemase activity in members of the genus Aeromonas. Antimicrob Agents Chemother 1995; 39: 346-349.

158. Walsh TR, Payne DJ, MacGowan AP, Bennett PM. A clinical isolate of Aeromonas sobria with three chromosomally mediated inducible $\beta$-lactamases: a cephalosporinase, a penicillinase and a third enzyme, displaying carbapenemase activity. J Antimicrob Chemother 1995; 35: 271-279.

159. Hayes MV, Thomson CJ, Amyes SGB. Three $\beta$-lactamases isolated from Aeromonas salmonicida, including a carbapenemase not detectable by conventional methods. Eur $J$ Clin Microbiol Infect Dis 1994; 13: 805-811.

160. Hayes MV, Thomson CJ, Amyes SGB. The 'hidden' carbapenemase of Aeromonas hydrophila. J Antimicrob Chemother 1996; 37: 33-44.

161. Bonfiglio G, Stefani S, Nicoletti G. Clinical isolate of a Xanthomonas maltophilia strain producing L-1-deficient and L-2-inducible $\beta$-lactamases. Chemotherapy 1995; 41: $121-124$

162. Paton R, Miles RS, Amyes SGB. Biochemical properties of inducible $\beta$-lactamases produced from Xanthomonas maltophilia. Antimicrob Agents Chemother 1994; 38: 2143-2149.

163. Payne DJ, Cramp R, Bateson JH, Neale J, Knowles D. Rapid identification of metallo- and serine $\beta$-lactamases. Antimicrob Agents Chemother 1994; 38: 991-996.

164. Baxter IA, Lambert PA. Isolation and partial purification of a carbapenem-hydrolysing metallo- $\beta$-lactamase from Pseudomonas cepacia. FEMS Microbiol Lett 1994; 122: 251-256.

165. Yotsuji A, Minami S, Inoue M, Mitsuhashi S. Properties of novel $\beta$-lactamase produced by Bacteroides fragilis. Antimicrob Agents Chemother 1983; 24: 925-929.

166. Thompson JS, Malamy MH. Sequencing the gene for an imipenem-cefoxitin-hydrolyzing enzyme (CfiA) from Bacteroides fragilis TAL 2480 reveals strong similarity between CfiA and Bacillus cereus $\beta$-lactamase II. J Bacteriol 1990; 172: 2584-2593.

167. Podglajen I, Breuil J, Collatz E. Insertion of a novel DNA sequence, IS1186, upstream of the silent carbapenemase gene cfiA, promotes expression of carbapenem resistance in clinical isolates of Bacteroides fragilis. Mol Microbiol 1994; 12 $105-114$.

168. Bandoh K, Ueno K, Watanabe K, Kato N. Susceptibility patterns and resistance to imipenem in the Bacteroides fragilis group species in Japan: a 4-year study. Clin Infect Dis 1993; 16 Suppl 4: S382-S386.

169. Watanabe M, Iyobe S, Inoue M, Mitsuhashi S. Transferable imipenem resistance in Pseudomonas aeruginosa. Antimicrob Agents Chemother 1991; 35: 147-151.

170. Osano E, Arakawa Y, Wacharotayankun R et al. Molecular characterization of an enterobacterial metallo- $\beta$-lactamase found in a clinical isolate of Serratia marcescens that shows imipenem resistance. Antimicrob Agents Chemother 1994; 38: $71-78$.

171. Minami S, Akama M, Araki $\mathrm{H}$ et al. Imipenem and cephem resistant Pseudomonas aeruginosa carrying plasmids coding for class B $\beta$-lactamase. J Antimicrob Chemother 1996; 37: 433-444.

172. Ito H, Arakawa Y, Ohsuka S, Wacharotayankun R, Kato N,
Ohta M. Plasmid-mediated dissemination of the metallo- $\beta$ lactamase gene bla $a_{I M P}$ among clinically isolated strains of Serratia marcescens. Antimicrob Agents Chemother 1995; 39: 824-829.

173. Senda K, Arakawa Y, Ito $\mathrm{H}$ et al. PCR detection of metallo$\beta$-lactamase producing Pseudomonas aeruginosa resistant to carbapenem. 96th Annual Meeting of ASM, New Orleans. Washington, DC, American Society for Microbiology. 1996: Abstract A45, p. 141.

174. Senda K, Arakawa Y, Nakashima K et al. Multifocal outbreaks of metallo- $\beta$-lactamase-producing Pseudomonas aeruginosa resistant to broad-spectrum $\beta$-lactams, including carbapenems. Antimicrob Agents Chemother 1996; 40: 349-353.

175. Ambler RP, Coulson AFN, Frere JM et al. A standard numbering system for the class A $\beta$-lactamases. Biochem $J$ 1991; 276: 269-270.

176. Shanahan PMA, Thomson CJ, Amyes SGB. $\beta$-Lactam resistance in normal faecal flora from South Africa. Epidemiol Infect 1995; 115: 243-253.

177. Nandivada LS, Amyes SGB. Plasmid-mediated $\beta$-lactam resistance in pathogenic Gram-negative bacteria isolated in South India. J Antimicrob Chemother 1990; 26: 279-290.

178. Shanahan PMA, Thomson CJ, Amyes SGB. $\beta$-Lactam resistance in aerobic faecal flora from general practice patients in the U.K. Eur J Clin Microbiol Infect Dis 1994; 13: $760-763$.

179. Henquell C, Chanal C, Sirot D, Labia R, Sirot J. Molecular characterization of nine different types of mutants among 107 inhibitor-resistant TEM $\beta$-lactamases from clinical isolates of Escherichia coli. Antimicrob Agents Chemother 1995; 39: 427-430.

180. Jelsch C, Lenfant F, Masson JM, Samama JP. Crystallization and preliminary crystallographic data on Escherichia coli TEM-1 $\beta$-lactamase. $J$ Mol Biol 1992; 223: 377-380.

181. Jelsch C, Mourey L, Masson JM, Samama JP. Crystal structure of Escherichia coli TEM-1 $\beta$-lactamase at $1.8-\mathrm{A}$ resolution. Proteins 1993; 16: 364-383.

182. Payne DJ, Marriott MS, Amyes SGB. Characterisation of a unique ceftazidime-hydrolysing $\beta$-lactamase, TEM-E2. $\mathrm{J} \mathrm{Med}$ Microbiol 1990; 32: 131-134.

183. Du Bois SK, Marriott MS, Amyes SGB. TEM- and SHVderived extended-spectrum $\beta$-lactamases: relationship between selection, structure and function. $J$ Antimicrob Chemother 1995; 35: 7-22.

184. Payne DJ, Amyes SGB. Transferable resistance to extendedspectrum $\beta$-lactams: a major threat or a minor inconvenience? $J$ Antimicrob Chemother 1991; 27: 255-261.

185. Sowek JA, Singer SB, Ohringer S et al. Substitution of lysine at position 104 or 240 of TEM-1 pTZ18R $\beta$-lactamase enhances the effect of serine-164 substitution on hydrolysis or affinity for cephalosporins and the monobactam aztreonam. Biochemistry 1991; 30: $3179-3188$.

186. Jarlier V, Nicolas MH, Fournier G, Philippon A. Extended broad-spectrum $\beta$-lactamases conferring transferable resistance to newer $\beta$-lactam agents in Enterobacteriaceae: hospital prevalence and susceptibility patterns. Rev Infect Dis 1988; 10: $867-878$

187. Knothe H, Shah P, Krcmery V, Antal M, Mitsuhashi S. Transferable resistance to cefotaxime, cefoxitin, cefamandole and cefuroxime in clinical isolates of Klebsiella pneumoniae. Infection 1983; 11: 315-317.

188. Huletsky A, Couture F, Leversque RC. Nucleotide sequence and phylogeny of SHV-2 $\beta$-lactamase. Antimicrob Agents Chemother 1990; 34: 1725-1732.

189. Huletsky A, Knox JR, Levesque RC. Role of Ser-238 and Lys- 240 in the hydrolysis of 3rd-generation cephalosporins by SHV-type $\beta$-lactamases probed by site-directed mutagenesis and 3-dimensional modeling. $J$ Biol Chem 1993; 268: 3690-3697.

190. Vatopoulos AC, Philippon A, Tzouvelekis LS, Komninou Z, Legakis NJ. Prevalence of a transferable SHV-5 type $\beta$ lactamase in clinical isolates of Klebsiella pneumoniae and Escherichia coli in Greece. J Antimicrob Chemother 1990; 26: $635-648$.

191. Bauernfeind A, Rosenthal E, Eberlein E, Holley M, Schweighart S. Spread of Klebsiella pneumoniae producing SHV-5 $\beta$-lactamase among hospitalized patients. Infection 1993; 21: $18-22$. 
192. Bradford PA, Urban C, Jaiswal A et al. SHV-7, a novel cefotaxime-hydrolyzing $\beta$-lactamase, identified in Escherichia coli isolates from hospitalized nursing home patients. Antimicrob Agents Chemother 1995; 39: 899-905.

193. Du Bois SK, Marriott MS, Amyes SGB. Can clavulanic acid reverse extended-spectrum $\beta$-lactamase mutations? ICAAC New Orleans. Washington, DC, American Society for Microbiology. 1993: 582 (Abstract)

194. Podbielski A, Schonling J, Melzer B, Warnatz K, Leusch HG Molecular characterization of a new plasmid-encoded SHVtype $\beta$-lactamase (SHV-2 variant) conferring high-level cefotaxime resistance upon Klebsiella pneumoniae. J Gen Microbiol 1991; 137: 569-578.

195. Thomson CJ, Amyes SGB. TRC-1: emergence of a clavulanic acid-resistant TEM $\beta$-lactamase in a clinical strain. FEMS Microbiol Lett 1992; 91: 113-117.

196. Vedel G, Belaaouaj A, Gilly L et al. Clinical isolates of Escherichia coli producing TRI $\beta$-lactamases - novel TEMenzymes conferring resistance to $\beta$-lactamase inhibitors. $J$ Antimicrob Chemother 1992; 30: 449-462.

197. Henquell C, Sirot D, Chanal C et al. Frequency of inhibitorresistant TEM $\beta$-lactamases in Escherichia coli isolates from urinary tract infections in France. J Antimicrob Chemother 1994; 34: 707-714.

198. Intercontinental Medical Statistics, Ruislip, Middlesex, UK. 1995

199. Cairns J. The chromosome of Escherichia coli. Cold Spring Harbor Symp Quant Biol 1963; 28: 43-46.

200. Gellert M, Misuuchi K, O'Dea MH, Nash HA. DNA gyrase: an enzyme that introduces superhelical turns into DNA. Proc Natl Acad Sci USA 1976; 73: 3872-3876.

201. Sugino A, Peebles CL, Kruezer KN, Cozzarelli NR. Mechanism of action of nalidixic acid: purification of Escherichia coli nalA gene product and its relationship to DNA gyrase and a novel nicking-closing enzyme. Proc Natl Acad Sci USA 1977; 74: 4767-4771.

202. Hooper DC. Quinolone mode of action. Drugs 1995; 49 Suppl 2: $10-15$.

203. Vincent S, Glauner B, Gutmann L. Lytic effect of two fluoroquinolones, ofloxacin and pefloxacin, on Escherichio coli W7 and its consequences on peptidoglycan composition. Antimicrob Agents Chemother 1991; 35: 1381-1385.

204. Cozens RM, Markiewicz Z, Tuomanen E. Role of autolysins in the activities of imipenem and CGP 31608, a novel penem, against slowly growing bacteria. Antimicrob Agents Chemother 1989; 33: 1819-1821

205. Wolfson JS, Hooper DC, McHugh GL, Bozza MA, Swartz MN. Mutants of Escherichia coli K12 exhibiting reduced killing by both quinolone and $\beta$-lactam antimicrobial agents. Antimicrob Agents Chemother 1990; 34: 1938-1943.

206. Munshi MH, Haider K, Rahaman MM, Sack DA, Ahmed ZV, Morshed MG. Plasmid-mediated resistance to nalidixic acid in Shigella dysenteriae type I. Lancet 1987; ii: 419-421.

207. Tanaka M, Ishii H, Sato K, Osada $Y$, Nishino T. Characterization of high level quinolone resistance in Staphylococcus aureus. 31st ICAAC, Chicago. Washington, DC, American Society for Microbiology. 1991: Abstract 808, p. 233.

208. Courvalin P. Plasmid-mediated 4-quinolone resistance: a real or apparent absence? Antimicrob Agents Chemother 1990; 34 681-684.

209. Yoshida H, Bogaki M, Nakamura S, Ubukata K, Konno M. Nucleotide sequence and characterization of the Staphylococcus aureus norA gene, which confers resistance to quinolones. J Bacteriol 1990; 172: 6942-6949.

210. Cambau E, Gutmann L. Mechanisms of resistance to quinolones. Drugs 1993; 45 Suppl 3: 5-23.

211. Yoshida H, Bogaki H, Nakamura M, Nakamura S. Quinolone resistance-determining region in the DNA gyrase gyrA gene of Escherichia coli. Antimicrob Agents Chemother 1990; 34 1271-1272.

212. Yamagishi J, Yoshida H, Yamagoshi M, Nakamura $\mathrm{S}$. Nalidixic acid-resistant mutations of the $\operatorname{gyr} B$ gene of Escherichia coli. Mol Gen Genet 1986; 204: 367-373.

213. Chapman JS, Georgopapadakou NH. Routes of quinolone permeation in Escherichia coli. Antimicrob Agents Chemother 1988; 32: 438-442.

214. Cohen SP, McMurry LM, Hooper DC, Wolfson JS, Levy SB Cross-resistance to fluoroquinolones in multiple-antibioticresistance (Mar) Escherichia coli selected by tetracycline or chloramphenicol: decreased drug accumulation associated with changes in addition to OmpF reduction. Antimicrob Agents Chemother 1989; 33: 1318-1325.

215. Ohshita Y, Hiramatsu K, Yokota T. A point mutation in norA gene is responsible for quinolone resistance in Staphylococcus aureus. Biochem Biophys Res Commun 1990; 172 $1028-1034$

216. Kaatz GW, Seo SM. Up regulation of norA1199 results in fluoroquinolone (FQ) resistance in Staphylococcus aureus (SA). 32nd ICAAC, Anaheim, CA. Washington, DC, American Society for Microbiology. 1992: Abstract 1481, p. 357

217. Trucksis M, Wolfson JS, Hooper DC. A novel locus conferring fluoroquinolone resistance in Staphylococcus aureus. J Bacteriol 1991; 173: 5854-5860.

218. Thornsberry C. Susceptibility of clinical bacterial isolates to ciprofloxacin in the United States. Infection 1994; 22 Supp 2: $\mathrm{S} 80-\mathrm{S} 89$.

219. Blondeau J, Yaschuk Y and the Canadian Ciprofloxacin Study Group. Canadian Ciprofloxacin Susceptibility Study: comparative study from 15 medical centers. Antimicrob Agents Chemother 1996; 40: 1729-1732.

220. Tillotson G, Herbert JJF. Comparison of antibiotic susceptibility levels in the United Kingdom. 4th European Congres of Clinical Microbiology and Infectious Diseases, Nice, France. 1989: Abstract 431, p 23

221. Kresken M, Hafner D, Mittermayer $\mathrm{H}$ et al. Prevalence of fluoroquinolone resistance in Europe. Infection 1994; 22 Suppl 2: S90-S98

222. Doern GV, Brueggemann A, Holley HP, Rauch AM Antimicrobial resistance of Streptococcus pneumoniae recovered from outpatients in the United States during the winter months of 1994 to 1995: results of a 30-center national surveillance study. Antimicrob Agents Chemother 1996; 40: $1208-1213$

223. Goldstein FW, Acar JF. Epidemiology of quinolone resistance: Europe and North and South America. Drugs 1995; 49 Supp 2: $36-42$.

224. Budnick LD, Schaefler S. Ciprofloxacin-resistant methicillinresistant Staphylococcus aureus in New York health care facilities, 1988. The New York MRSA Study Group. Am Public Health 1990; 80: 810-813.

225. Schaberg DR, Dillon WI, Terpenning MS, Robinson KA Bradley SF, Kauffman CA. Increasing resistance of enterococci to ciprofloxacin. Antimicrob Agents Chemother 1992; 36: $2533-2535$.

226. King A, Phillips I, Amyes SGB, Paton R, Levin C, Tillotson G. MIC audit of routine ciprofloxacin sensitivity testing. Drugs 1993; 45 Suppl 3: 163-164.

227. Thomson CJ, Paton RH, Hood J, Miles RS, Amyes SGB Antibiotic resistance in urinary bacteria isolated in central Scotland. Int J Antimicrob Agents 1992; 1: 223-228.

228. MacGowan AP, Brown NM, Holt HA, Lovering AM, McCulloch SY, Reeves DS. An eight-year survey of the antimicrobial susceptibility patterns of 85,971 bacteria isolated from patients in a district general hospital and the local community. J Antimicrob Chemother 1993; 31: 543557.

229. Amyes SGB, Baird DR, Crook DW et al. A multicentre study of the in-vitro activity of cefotaxime, cefuroxime, ceftazidime, ofloxacin and ciprofloxacin against blood and urinary pathogens. J Antimicrob Chemother 1994; 34: 639-648.

230. Frost JA, Kelleher A, Rowe B. Increasing ciprofloxacin resistance in salmonellas in England and Wales 1991-1994. J Antimicrob Chemother 1996; 37: 85-91.

231. Brown JC, Shanahan PMA, Jesudason MV, Thomson CJ, Amyes SGB. Mutations responsible for reduced susceptibility to 4-quinolones in clinical isolates of multi-resistant Salmonella typhi in India. J Antimicrob Chemother 1996; 37 : $891-900$

232. Gillespie SH, Fox R, Patel S, Ngowi F, Tillotson GS Antibiotic susceptibility of Enterobacteriaceae isolated from patients in Northern Tanzania. J Antimicrob Chemother 1992; 29: $227-229$.

233. Coronado VR, Edwards JR, Culver DH, Gaynes RP and the National Nosocomial Infections Surveillance (NNIS) System. Ciprofloxacin resistance among nosocomial Pseudomonas aeruginosa and Staphylococcus aureus in the United States. Infect Control Hosp Epidemiol 1995; 16: 71-75.

234. Reina J, Borrell N, Serra A. Emergence of resistance to 
erythromycin and fiuoroquinolones in thermotolerant Campylobacter strains isolated from feces 1987-1991. Eur J Clin Microbiol Infect Dis 1992; 11: 1163-1166.

235. Child J, Andrews J, Boswell F, Brenwald N, Wise R. The invitro activity of CP99,219, a new naphthylpyridone antimicrobial agent: a comparison with fluoroquinolone agents. $J$ Antimicrob Chemother 1995; 35: 869-876.

236. Marco F, Jones RN, Hoban DJ, Pignatari AC, Yamane N, Frei R. In-vitro activity of OPC-17116 against more than 6000 consecutive clinical isolates: a multicentre international study. $J$ Antimicrob Chemother 1994; 33: 647-654.

237. Flamm RK, Vojtko C, Chu DTW et al. In vitro evaluation of ABT-719, a novel DNA gyrase inhibitor. Antimicrob Agents Chemother 1995; 39: 964-970.

238. Hoshino K, Kutamura A, Morrissey I, Sato K, Kato J-I, Ikeda H. Comparison of inhibition of Escherichia coli topoisomerase IV by quinolones with DNA gyrase inhibition Antimicrob Agents Chemother 1994; 38: 2623-2627.

239. Timmis KN, Gonzalez-Carrero MI, Sekizaki T, Rojo F. Biological activities specified by antibiotic resistance plasmids. J Antimicrob Chemother 1986; 18 Suppl C:1-12.

240. Cundliffe E. How antibiotic-producing organisms avoid suicide. Annu Rev Microbiol 1989; 43: 207-233.

241. Leveau JY, Bouix M. Microbiologie industrielle. Les microorganismes d'intérêt industriel. Collection Sciences et Techniques Agro-Alimentaires. Technique \& Documentation, Paris, Lavoisier.

242. Davies J, Houk C, Yagisawa M, White TJ. Occurrence and function of aminoglycoside-modifying enzymes. In: Sebek $\mathrm{OK}$, Laskin AJ (eds) Genetics of industrial microorganisms. Washington, DC, American Society for Microbiology. 1979: $166-169$.

243. Datta N, Hughes VM. Plasmids of the same Inc groups in Enterobacteria before and after the medical use of antibiotics. Nature 1983; 306: 616-617.

244. Jacoby GA. Extrachromosomal resistance in gram-negative organisms: the evolution of $\beta$-lactamase. Trends Microbiol 1994; 2: $357-360$

245. Courvalin P. Transfer of antibiotic resistance genes between gram-positive and gram-negative bacteria. Antimicrob Agents Chemother 1994; 38: 1447-1451.

246. Committee on Human Health Risk Assessment of Using Subtherapeutic Antibiotics in Animal Feeds. Human health risks with the subtherapeutic use of penicillin or tetracyclines in animal feed. Washington, DC, National Academy Press. 1989.

247. Pérez-Trallero E, Zigorraga C. Resistance to antimicrobial agents as a public health problem: importance of the use of antibiotics in animals. Int $J$ Antimicrob Agents 1995; 6: 59-63.

248. Donnelly JP, Voss A, Witte W, Murray BE. Does the use in animals of antimicrobial agents, including glycopeptide anti- biotics, influence the efficacy of antimicrobial therapy in humans? J Antimicrob Chemother 1996; 37: 389-390.

249. Trieu-Cuot P, Courvalin P. Evolution and transfer of aminoglycoside resistance genes under natural conditions $J$ Antimicrob Chemother 1986; 18 Suppl C: 93-102.

250. Endtz HP, Ruijs GJ, Van Klingeren B, Jansen WH, van der Reyden T, Mouton RP. Quinolone resistance in campylobacter isolated from man and poultry following the introduction of fluoroquinolones in veterinary medicine. $J$ Antimicrob Chemother 1991; 27: 199-208.

251. Linton AH. Flow of resistance genes in the environment and from animals to man. $J$ Antimicrob Chemother 1986; 18 Suppl C: $189-197$

252. Anderson ES. The ecology of transferable drug resistance in the enterobacteria. Annu Rev Microbiol 1968; 22: 131-180.

253. Young H-K. Antimicrobial resistance spread in aquatic environments. J Antimicrob Chemother 1993; 31: 627-635.

254. Hawkey PM. Resistant bacteria in the normal human flora. $J$ Antimicrob Chemother 1986; 18 Suppl C: 133-139.

255. Bergogne-Bérézin E. Resistance of Acinetobacter spp. to antimicrobials. Overview of clinical resistance patterns and therapeutic problems. In: Bergogne-Bérézin E, Joly-Guillou ML, Towner KJ (eds) Acinetobacter, microbiology, epidemiology, infections, management. Boca Raton, CRC Press. 1996: 133-138.

256. Jacobson KL, Cohen SH, Inciardi JF et al. The relationship between antecedent antibiotic use and resistance to extendedspectrum cephalosporins in group I $\beta$-lactamase-producing organisms. Clin Infect Dis 1995; 21: 1107-1113.

257. Cohen ML. Antimicrobial resistance: prognosis for public health. Trends Microbiol 1994; 2: 422-425.

258. Courcol RJ, Pinkas M, Martin GR. A seven year survey of antibiotic susceptibility and its relationship with usage. $J$ Antimicrob Chemother 1989; 23: 441-451.

259. Buisson Y, Tran Van Nhieu G, Ginot L et al. Nosocomial outbreaks due to amikacin-resistant tobramycin-sensitive Acinetobacter species: correlation with amikacin usage. $J$ Hosp Infect 1990; 15: 83-93.

260. Nissinen A, Grönroos P, Huovinen $\mathrm{P}$ et al. Development of $\beta$ lactamase-mediated resistance to penicillin in middle-ear isolates of Moraxella catarrhalis in Finnish children, 1978-1993. Clin Infect Dis 1995; 21: 1193-1196.

261. Janknegt R, van der Meer JWM. Sequential therapy with intravenous and oral cephalosporins. J Antimicrob Chemother 1994; 33: 169-177.

262. Quintiliani R, Nightingale C. Transitional antibiotic therapy. Infect Dis Clin Pract 1994; 3 Suppl 3: S161-S167.

263. Mandell GL. Delivery of antibiotics by phagocytes. Clin Infect Dis 1994; 19: 922-925.

264. Kreuter J. Liposomes and nanoparticles as vehicles for antibiotics. Infection 1991; 19 Suppl 4: S224-S228. 